University of South Florida

DIGITAL COMMONS

Digital Commons @ University of

@ UNIVERSITY OF SOUTH FLORIDA

South Florida

USF Tampa Graduate Theses and Dissertations

USF Graduate Theses and Dissertations

November 2017

\title{
Music Ensemble Participation: Personality Traits and Music Experience
}

Tracy A. Torrance

University of South Florida, ttorranc@mail.usf.edu

Follow this and additional works at: https://digitalcommons.usf.edu/etd

Part of the Other Education Commons

\section{Scholar Commons Citation}

Torrance, Tracy A., "Music Ensemble Participation: Personality Traits and Music Experience" (2017). USF Tampa Graduate Theses and Dissertations.

https://digitalcommons.usf.edu/etd/7100

This Dissertation is brought to you for free and open access by the USF Graduate Theses and Dissertations at Digital Commons @ University of South Florida. It has been accepted for inclusion in USF Tampa Graduate Theses and Dissertations by an authorized administrator of Digital Commons @ University of South Florida. For more information, please contact digitalcommons@usf.edu. 
Music Ensemble Participation: Personality Traits and Music Experience

by

\author{
Tracy A. Torrance \\ A dissertation submitted in partial fulfillment \\ of the requirements for the degree of \\ Doctor of Philosophy in Music \\ with a concentration in Music Education \\ School of Music \\ College of The Arts \\ University of South Florida
Major Professor: Jennifer A. Bugos, Ph.D.
Darlene DeMarie, Ph.D.
C. Victor Fung, Ph.D.
William Hayden, D.A.
David A. Williams, Ph.D.

Date of Approval:

November 15, 2017

Keywords: Music Psychology, Music Education, Big Five, Music Engagement

Copyright (C) 2017, Tracy A. Torrance 


\section{ACKNOWLEDGEMENTS}

There are a number of people I would like to thank who have travelled this doctoral path with me. First and foremost, I would like to thank my parents, Robert and Barbara Torrance, for their love, support, and belief in me. I would never have gotten this far in my academic career without them and the rest of my family. I will be forever grateful to my committee members, Dr. Jennifer Bugos, Dr. Darlene DeMarie, Dr. C. Victor Fung, Dr. William Hayden, and Dr. David Williams, for their guidance and never-ending patience. Thank you to Dr. James Bass for sharing his passion for choral music, setting high expectations, and inspiring me to meet those expectations. I would also like to thank Craig and Maria Elena D'Amico, who gave me a "home away from home" many a night so I would not have to make the hour-long commute home in the wee hours of the morning. To Yvonne Weir, Lois Pound, Dr. Jerry Sergent, Peggy Sergent, Lynn Leonard, and Cindy Bonnett whose continued encouragement kept me focused on the goal, thank you. I would also like to acknowledge the following people who were instrumental in the completion of this research: Jason Bombaugh, Dr. Chris Brown, Mary Ellis, Ron Ellis, Dr. Beth

Gibbs, Dr. Jonathan Kladder, Joel Pagán, Giovanni Perez, Devin Plant, Dr. Doreen Rao, Dr. José Ruiz, Robert Schaer, Dr. Amanda Schlegel, Veva Scott, Dr. Greg Springer, and Dr. Sandra Vernon-Jackson. And finally, to my niece, Adia Torrance, who is a constant reminder of my love of music and why I became a teacher. 


\section{TABLE OF CONTENTS}

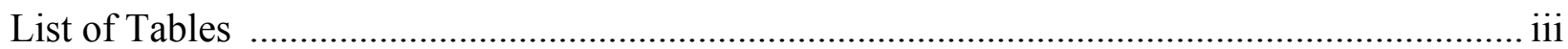

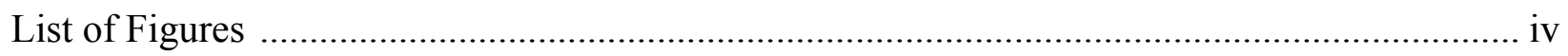

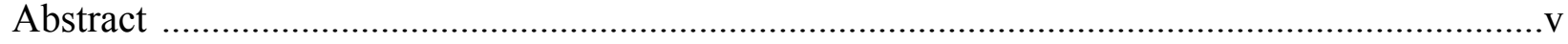

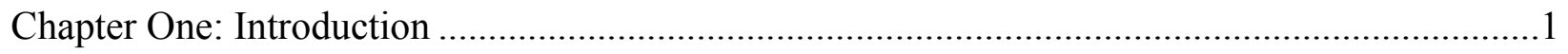

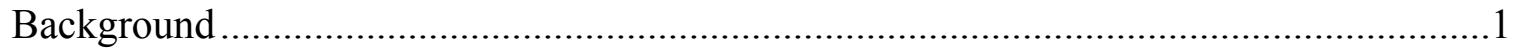

Significance

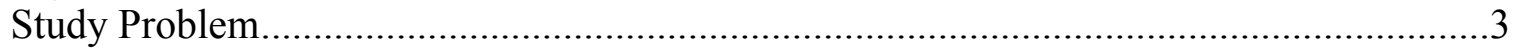

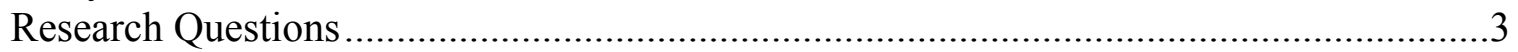

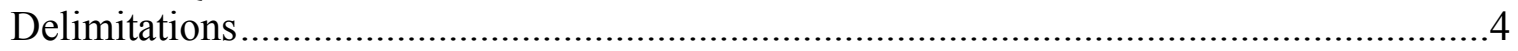

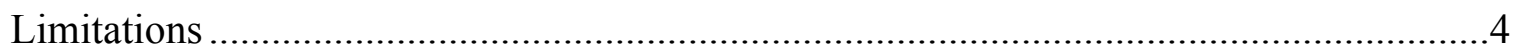

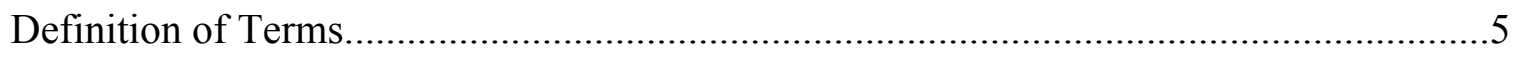

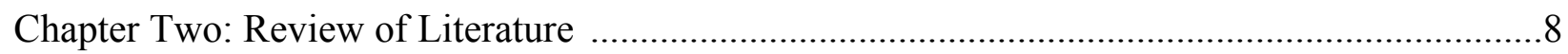

Theoretical Principles Underlying Personality ……………............................................ 8

Historical Overview of Personality Inventories.................................................................

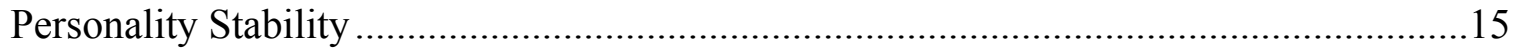

Personality, Cognitive Style, and Learning Styles........................................................16

Personality Traits of Creative People ………………….................................................17

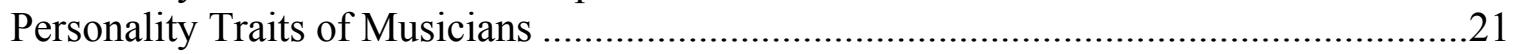

Personality Type and Musical Instrument Choice .........................................................26

Gender and Musical Instrument Choice ……………................................................29

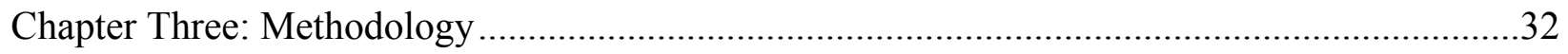

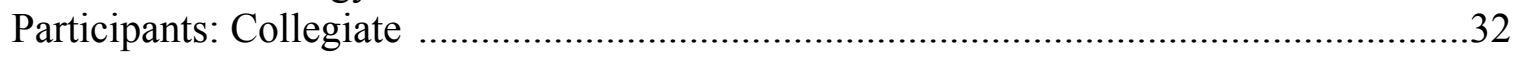

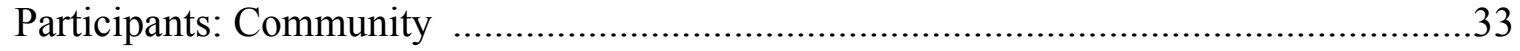

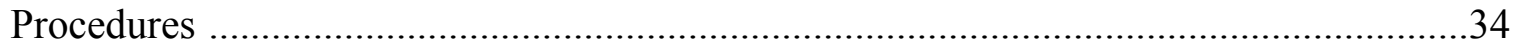

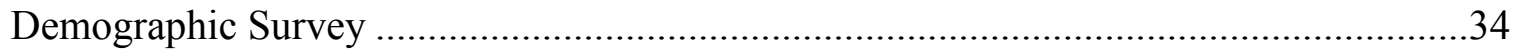

Personality Measurement Instrument ………………..............................................34

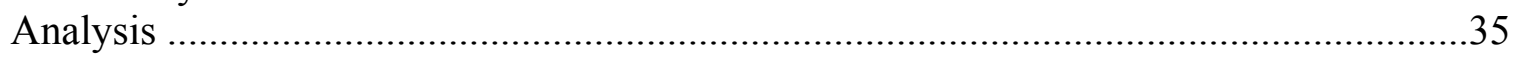

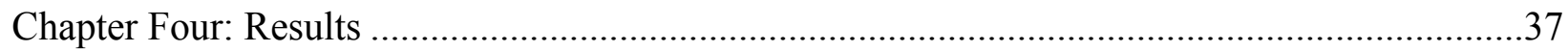

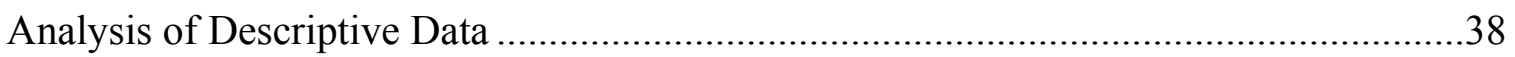

Participants by Gender, Race/Ethnicity, and Age.................................................38

Current Ensemble Participation ......................................................................39

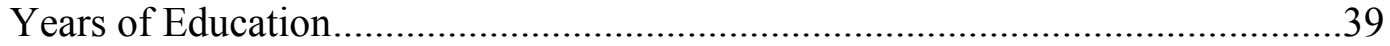

RQ1

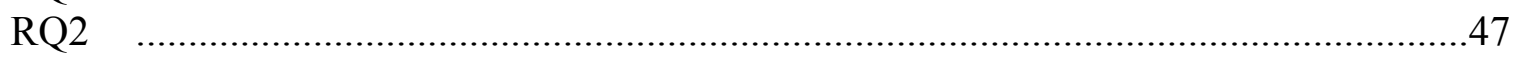




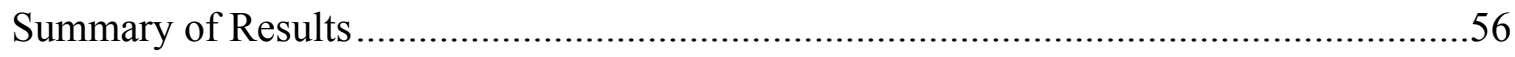

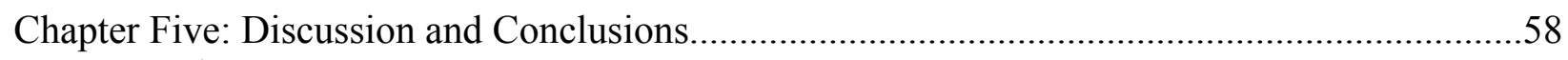

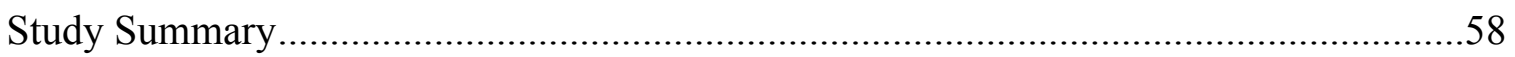

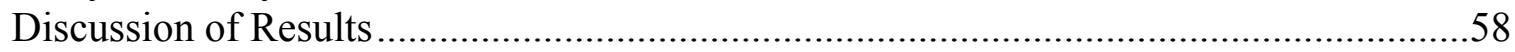

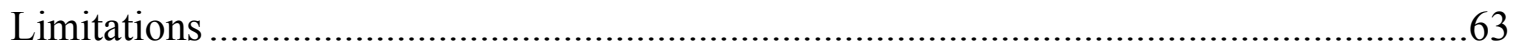

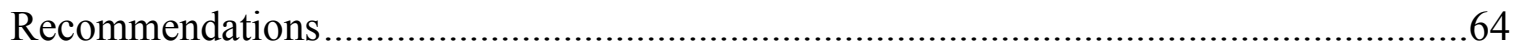

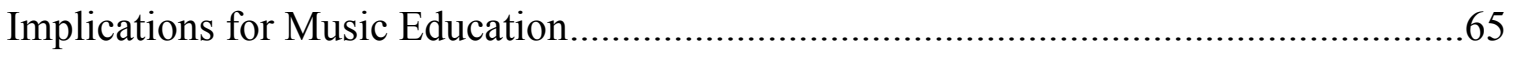

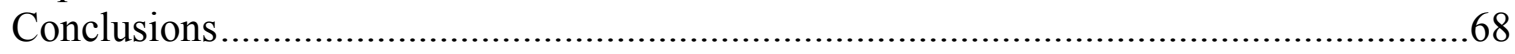

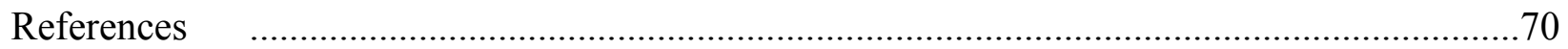

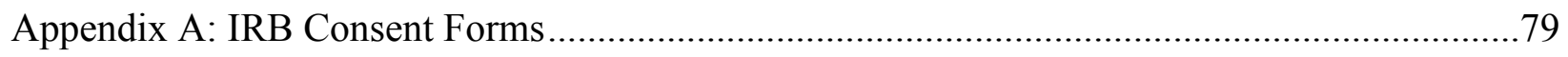

Appendix B: Collegiate Demographic Questions .......................................................................

Appendix C: Community Demographic Questions .....................................................................

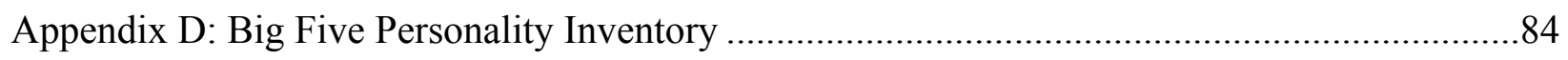

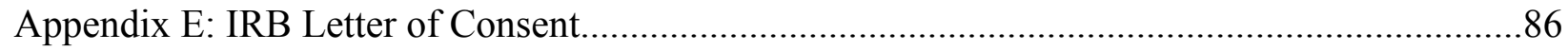

Appendix F: Graphs of Personality Mean Scores by Current Ensemble

Participation (Collegiate, Community, Other, No music

ensemble participations) ............................................................................................. 88 


\section{LIST OF TABLES}

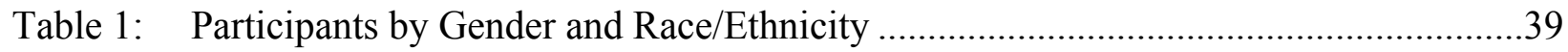

Table 2: Participants by Age and Current Ensemble Participation.........................................39

Table 3: Chi-square for Gender and Current Ensemble Participation ....................................40

Table 4: Means, Standard Deviation, Skewness, and Kurtosis for Personality Traits, Instrumentalists and Vocalists

Table 5: Means, Standard Deviation, Skewness, and Kurtosis for Personality Traits

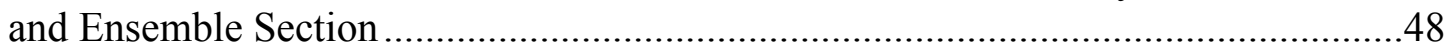

Table 6: Agreeableness Pairwise Comparison ...............................................................51

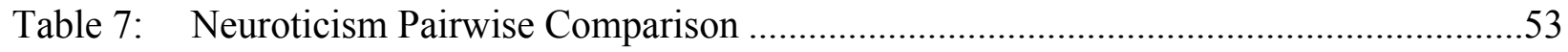

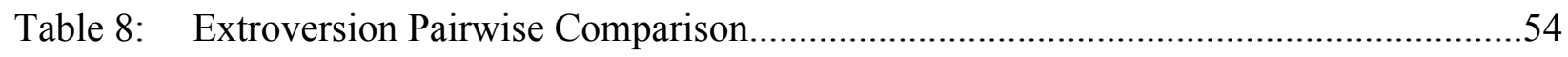

Table 9: Openness to Experience Pairwise Comparison......................................................60 


\section{LIST OF FIGURES}

Figure 1: Graph for Agreeableness Mean Scores by Gender and Instrument

Choice (Instrumentalist, Vocalist, or No Ensemble Participation)

Figure 2: Graph for Neuroticism Mean Scores by Gender and Instrument

Choice (Instrumentalist, Vocalist, or No Ensemble Participation)

Figure 3: Graph for Extroversion Mean Scores by Gender and Instrument

Choice (Instrumentalist, Vocalist, or No Ensemble Participation)

Figure 4: Graph for Openness to Experience Mean Scores by Gender and Instrument Choice (Instrumentalist, Vocalist, or No Ensemble

Participation).....

Figure 5: Graph for Conscientiousness Mean Scores by Ensemble Section (Strings, Winds, Brass, Percussion, Keyboard, Soprano Vocalist, Alto Vocalist, Tenor Vocalist, Bass Vocalist).

Figure 6: Graph for Agreeableness Mean Scores by Ensemble Section (Strings, Winds, Brass, Percussion, Keyboard, Soprano Vocalist, Alto Vocalist, Tenor Vocalist, Bass Vocalist).

Figure 7: Graph for Neuroticism Mean Scores by Ensemble Section (Strings, Winds, Brass, Percussion, Keyboard, Soprano Vocalist, Alto Vocalist, Tenor Vocalist, Bass Vocalist)

Figure 8: Graph for Extroversion Mean Scores by Ensemble Section (Strings, Winds, Brass, Percussion, Keyboard, Soprano Vocalist, Alto Vocalist, Tenor Vocalist, Bass Vocalist)

Figure 9: Graph for Openness to Experience Mean Scores by Ensemble Section (Strings, Winds, Brass, Percussion, Keyboard, Soprano Vocalist, Alto Vocalist, Tenor Vocalist, Bass Vocalist) 


\begin{abstract}
The personality of musicians, artists, and other creative persons is of considerable interest to researchers and educators who seek to identify traits associated with musical behaviors. Personality traits can influence music behaviors such as instrument choice, ensemble choice, practice habits, and musical experience, which may contribute to continued music participation. The purpose of this study is to explore the relationships between personality type, music ensemble section, instrument choice (vocal or instrumental), and musical experience in college students and individuals who choose to continue participation after college. Few studies have concentrated on personality characteristics of ensemble members at the collegiate level and after formal education ceases. This is particularly relevant as personality characteristics may not be stable with age. This study examined the following questions: 1) To what extent do personality traits (Agreeableness, Conscientiousness, Extroversion, Neuroticism, and Openness to Experience) relate to ensemble choice (instrumental, vocal no musical ensemble participation) and gender?; and 2) To what extent do personality traits (Agreeableness, Conscientiousness, Extroversion, Neuroticism, and Openness to Experience) relate to ensemble section (e.g., brass, alto voice)? Participants were given a survey containing demographic questions and the Big Five Personality Inventory IPIP (Goldberg, 1992). Results showed that vocalists scored higher in Extroversion and Agreeableness compared to instrumentalists, and Instrumentalists scored higher in Neuroticism than vocalists. These results are consistent with previous research findings. This study has many implications for ensemble directors, such as rehearsal structure and repertoire choice. Music educators could also benefit from this knowledge when developing lesson plans
\end{abstract}


and group assignments. Understanding different personality traits would also help ensemble members with communication within the ensemble. 


\section{CHAPTER ONE}

\section{INTRODUCTION}

\section{Background}

Musicians and creative individuals share unique personality traits that are of considerable interest to researchers and educators who seek to identify relationships associated with musical behaviors. While many have examined personality differences in young children, high school, and professional musicians compared to the general population (Bell \& Cresswell, 1984; Buttsworth \& Smith, 1995; Cameron, Duffy, \& Glenwright, 2014; Chang, 2007; Corrigall, Schellenberg, \& Misura, 2013; Cutietta \& McAllister, 1997; Kemp, 1981, 1981a, 1986; Langendörfer, 2008; Reardon, 2008), few studies have examined the personality traits associated with continued musical engagement through adulthood.

Lifelong learning in adulthood is represented by many different stages of development. Many young adults at the university level, both music majors and non-music majors, continue to pursue music rigorously after graduation. Added to recent college graduates are the Baby Boomers who are nearing retirement or have already retired. Many Boomers ceased participating in music ensembles after high school or college for various reasons (e.g., work schedule and/or family obligations) and are now looking for a musical outlet. So, for this reason, intergenerational ensembles have become more common. Inter-generational marching bands (i.e., The Second Time Arounders in Florida and the Get a Life Band in Oregon) have as many 450 members mostly between the ages of 18 and 80 . 
Given the large population of adults who have access to music participation opportunities throughout the lifespan, more information is needed to assist music educators, directors, and researchers, regarding personality traits of those who enroll in adult music ensembles. Understanding these traits will enable educators to better serve their constituents through music selection, instrument assignments, and sectional rehearsals. For instance, research suggests that personality traits are linked to genre choice, thus enabling directors to consider the preferences of their ensemble in order to make decisions regarding repertoire selection (Rentfrow \& Gosling, 2003).

The purpose of this research is to examine personality traits between 1) collegiate musicians enrolled in instrumental and vocal ensembles and 2) those who continue to perform in community ensembles after graduation.

\section{Significance}

The study of personality type has led to a clearer understanding of how and why individuals respond to certain environmental and social situations. Personality has been linked to choice of spouse (Buss, 2008; McCrae \& Costa, 2008; Russell \& Wells, 1991), social circles (Buss, 2008; Hogan, 1983; Hogan \& Warrenfeltz, 2003), and career path (John, Naumann, \& Soto, 2008; Myers, 1985). Within the musical domain, this could be the difference between individuals choosing to play in a jazz band instead of a marching band, or enrolling in an $a$ capella choir instead of a mass choir. Genre choice has also been associated with individualdifferences in variables such as Openness to Experience, verbal intelligence and political orientation (Rentfrow \& Gosling, 2003). A 2011 study utilizing the Big Five found a robust positive relationship between Openness to Experience and Jazz music preference and Neuroticism and Classical music preference (Dunn, DeRuyter, \& Bouwhuis, 2012). Genre 
preference, in turn, may influence ensemble choice as well.

The personality of professional music educators has also been a topic of interest to researchers. Personality plays a major role in successful teaching (Kemp, 1982a). By investigating the personality of music educators, not only can we examine their teaching style, but we can also look at their professional career experience. This information could lead to a better understanding of the factors of teacher retention (i.e., stress, burnout, and job satisfaction) (Steele \& Young, 2011).

Study Problem

Many conductors and music educators know very little about the individual personalities of their ensemble members. Understanding the personalities of ensemble members would not only assist music educators and ensemble conductors to improve communication with their ensembles, but it would also help build relationships within the ensemble. Although controversial, some research has associated personality with learning style and how individuals assimilate information (Corrigall, Schellenberg, \& Misura, 2013). This information could assist in tailoring lesson and rehearsal plans, as well as repertoire, to achieve maximum productivity. At the collegiate level, this information may also be helpful when pairing music education students with cooperating teachers for internship or practicum experiences.

Research Questions

1. To what extent do personality traits (Agreeableness, Conscientiousness, Extroversion, Neuroticism, and Openness to Experience) relate to ensemble choice (instrumental, vocal, no musical ensemble participation) and gender? 
2. To what extent do personality traits (Agreeableness, Conscientiousness, Extroversion, Neuroticism, and Openness to Experience) relate to ensemble section (e.g., brass, alto voice)?

\section{Delimitations}

This study was not concerned with

- The personality of $\mathrm{K}-12$ students

- Musicians not engaged in music ensembles

- The personality of conductors and professional musicians

\section{Limitation}

- The measurement instrument, The Big Five Inventory (Goldberg, 1992), was administered both online and by paper and pencil. While the online version can be a convenient method for mass distribution, it is not without its limitations. Since the survey can be administered anywhere, the environment in which the participants completed the survey was inconsistent. If there were distractions such as noise or lighting issues, it is possible that a participant may have answered differently than if he or she was in a controlled environment. Completion of this measure in a group setting may be influenced by social desirability. However, studies have shown that well-designed Internet surveys can open the door to a more diverse population of participants and are similar in reliability to the paper-pencil version (Gosling, Vazire, Srivastava, \& John, 2004; Skitka \& Sargis, 2005). 


\section{Definition of Terms}

Big Five Personality Inventory (BFI) Goldberg's IPIP is a 50-item inventory of short phrases measuring five individual personality dimensions: Agreeableness, Conscientiousness, Extroversion, Neuroticism and Openness to Experience (Johnson, 2015; De Raad, 2000; Zhang, 2002).

- Agreeableness: People who score high on Agreeableness are unselfish, have a sympathetic personality, are eager to help and respect others' beliefs. Those who score low on Agreeableness often speak their mind more freely without thought of the consequences, and they lack interpersonal skills.

- Conscientiousness: People with high Conscientiousness scores generally set concise goals and work diligently towards them. They are also reliable and trustworthy. On the contrary, those who score low on Conscientiousness are often disorganized in their work and live for the moment.

- Extroversion: People who score high in Extroversion tend to be outgoing, sociable, self-confident and work well with others. Those scoring low on Extroversion often prefer to work alone and can appear to be unsociable to others.

- Neuroticism: People with high scores in Neuroticism are often emotionally unstable, easily upset and have low self-esteem. Low scorers would be described as patient, optimistic, relaxed, and calm.

- Openness to Experience: Those who score high on Openness to Experience tend to have an active imagination, are independent thinkers, and are less 
conservative. Low scorers tend to think in simple terms, are practical and down to earth.

Engagement in music is defined as actively participating in the creation of music as compared to the passive activity of listening to music.

Ensemble is a group of musicians who perform together.

Formal training consists of private music instruction; applied instrumental and/or vocal lessons.

Junior Eysenck Personality Questionnaire (JEPQ) is an 81-item personality assessment for children 7-17 years of age. Based on the adult version, the JEPQ measures Extroversion-Introversion, Psychoticism, Neuroticism, and includes a Lie scale and takes approximately 10-15 minutes to administer.

Myers-Briggs Type Indicator (MBTI) is a personality inventory based on Carl Jung's theory of types (Jung, 1921). Personalities can be defined by a typological combination of "attitudes" (extroversion-introversion) and "functions" (thinkingfeeling, sensing-intuiting, and judging-perceiving) (Barenboim \& Winter, 2008). Individual preference is measured in each of the four dichotomies, evolving into one of 16 distinctive personality types. Description of each dichotomy follows:

- Extroversion - Looks outward towards others for energy

- Introversion - Looks inward, towards self for energy

- Sensing - Depends on concrete information for decision making

- Intuitive - Depends on their own understanding of how things work

- Thinking - Bases decisions on logic and reasoning

- Feeling-Bases decisions on emotion 
- Judging - Likes things planned and organized

- Perceiving - Tends to be spontaneous, flexible

Non-musician is an individual not currently engaged in making music

Pathemia a personality trait used to describe individuals who are emotionally immature with poorly fixated feelings; unrealistic attitude.

Personality refers to individual differences in characteristic patterns of thinking, feeling, and behaving (APA.org).

Sixteen Personality Factor Model (16PF) is a self-reporting personality inventory created by Raymond Cattell, which measures 16 personality traits such as warmth, openness to change, emotional stability, etc. 


\section{CHAPTER TWO}

\section{REVIEW OF LITERATURE}

The review of relevant literature is a synthesis of research defining personality and the Five Factor Model (FFM) or "Big Five," discussing the personality traits of creative individuals and musicians, gender, and personality as it pertains to instrument choice, personality in aging, and personality stability.

\section{Theoretical Principles of Personality}

Personality psychology is studied to make sense of how individuals "are like all other people, like some other people, and like no other person" (Little, 2016). Personality theorists have debated the definition of personality, but two theories have pervaded: human nature and individual differences (Buss, 1984). Human nature is what motivates us in our daily journey, as well as decision-making, how we respond to our environment, and ways we influence the people and world around us. These are the shared, common human characteristics that are, for the most part, universal. These motives range from the aggressive and sexual instincts proposed by Freud (1953/1905) to Hogan's (1983) theory of "get along and get ahead" (having good rapport with other individuals and attaining a higher social status). Hogan and Warrenfeltz (2003) suggest humans have three innate biological needs: (1) Acceptance and approval; (2) power, status, and control of resources; and (3) predictability and order, which coincide with the "get along and get ahead" theory. However, human nature is far more complex and includes the typical ways humans make decisions (e.g., spouse and career selection), respond to environmental stimuli 
(e.g., fear of crowds or heights), and how individuals affect their environment (Buss, 2008, p. 30).

The second theory, individual differences, refers to characteristic patterns of thinking, feeling, and behaving, and examines how people contrast from amid the countless dimensions of possible differences. Environmental and genetic sources of variation may be the origin of individual differences, in principle. For example, most individuals have the psychological mechanism for jealousy; however, the degree of jealousy each individual exhibits will vary based on environmental conditions (Buss, 2008). Environmental and/or genetic sources of variation may also influence individual differences.

It is difficult to separate one theory from the other for a complete understanding of personality. In theory, both models should be combined to get the complete picture of an individual: understanding the individual differences of how people of feel, behave, and think as well as how various parts of personality come together as a whole to create an individual's personality. According to Buss (2011): “(1) If humans have a human nature, and (2) if the components of that nature were "designed" to perform certain functions, then (3) a non-arbitrary means for identifying the most important individual differences involves discovering those differences that affect the performance of that function" (p. 31).

\section{Historical Overview of Personality Inventories}

Evidence of the study and appraisal of personality characteristics can be traced to antiquity. For more than 3000 years, the Chinese government used an elaborate system of competitive examinations, some assessing personality characteristics, for selecting government personnel (DuBois, 1970). Throughout history, mostly through observation, there has been evidence of evaluation of personality and character to make personality judgment. However, it 
was not until the $19^{\text {th }}$ century that the need for evaluating underlying personality took a more objective focus. Many physicians believed that personality could be determined by careful observation of an individual's physical characteristics, such as the shape of the eyes or size of one's head. This phenomenon was known as phrenology. Although this theory was popular, many in the scientific community did not accept it, and the phenomenon was short-lived. As a result of this movement, there was a renewed interest in personality assessment by the scientific community.

Since the publication of the first personality inventory 100 hundred years ago, thousands of instruments have been developed. Woodworth's Personality Data Sheet (1917), which most researchers would agree is the earliest self-report personality measure, was created for the United States Army during World War I in order to detect psychiatric problems in recruits (Woodworth, 1919). However, it was not completed in time and was not published until after the war was over. Although is it was not used for its original purpose, Woodworth's Personality Data Sheet would be the beginning of a whole new method of examining personality.

The early part of the $20^{\text {th }}$ century saw a growing interest in personality research (Barenbaum \& Winter, 2008) and the need to develop a practical taxonomy (John, Naumann, \& Soto, 2008). In 1921, Gordon W. Allport published the first American review of psychological literature based on personality and character. He later collaborated with Henry S. Odbert to create a list of over 4,500 personality traits (Allport \& Odbert, 1936), however, the list was too large to be of practical value (Allport \& Odbert, 1936). Utilizing Allport and Odbert's list, Raymond Cattell (1943) eliminated 99\% of the terms through semantic and empirical cluster procedures, bringing the list to 35 traits. After completing several oblique factor analyses, 12 factors were identified which were integrated into the 16 Personality Factors (16PF) inventory 
(Cattell, 1943, 1945a, 1945b). Fiske (1949) followed Cattell's lead and simplified the descriptions, which would later be termed as the Big Five. In 1961, Tupes and Christal reanalyzed correlation matrices and found five reoccurring factors (1961, pg.14). Utilizing Cattell's list, several other investigators replicated the five-factor structure (Borgatta, 1964; McCrae \& Costa, 1987; Digman \& Takemoto-Chock, 1964; Norman, 1963). These factors became known as the "Big Five," a term assigned to the factors by Lew Goldberg (1981). The term is not meant to imply that personality can be simply broken down to only five traits, but into five dimensions summarizing a larger number of unique personality traits (John, Naumann \& Soto, 2008).

The Five-Factor Model (FFM) is a stratified organization of personality traits, which are divided into five basic dimension: (I) Extroversion (or Surgency), (II) Agreeableness, (III) Conscientiousness (or Dependability), (IV) Neuroticism (or Emotional Stability), and (V) Culture (Goldberg, 1990). While personality theorists agree there are five dimensions, they cannot agree on trait terms. For instance, Goldberg's Big 5 IPIP (1992) utilizes the term Agreeableness for Factor II, whereas Cattell (1943) utilizes the term Pathemia (John, Robbins, \& Pervin, 2008). Factor V has been labeled as Culture (Norman, 1963), Openness (McCrae \& Costa, 1987) and Intellect (Digman \& Takemoto-Chok, 1981; Peabody \& Goldberg, 1989). However, the trait-descriptive adjectives for each factor remain consistent for each factor.

\section{Extroversion}

Each specific personality trait illustrates the magnitude or frequency of an individual's behaviors, feelings or thoughts as compared to other individuals. All five traits exist in everyone; however, it is to what degree the trait manifests itself which differentiates individuals and should be regarded as continuous, not an attribute that an individual possesses or does not possess. For 
instance, individuals who score high on the first factor, Extroversion (I), tend to be energetic and action oriented. They enjoy being with other people, have many friends, are comfortable in group situations, and do not mind being the center of attention. Social status is important to them and they tend to be in leadership positions (John, Naumann, \& Soto, 2008). Extroverts are action oriented and like to make things happen. This can sometimes lead them to act too quickly by not thi king the situation through thoroughly. Extroverts also have a tendency to "think out loud" and ask others for their opinions when solving problems (Myers-Briggs.org).

On the opposite end of the pole, individuals who score lower on Extroversion do not exhibit the same high energy and activity levels as those who score higher. They tend to be quiet and appear to be disengaged from the social world. This should not be misconstrued for depression or shyness. Unlike extroverts, they do not need great amounts of social interaction. In general, introverts avoid conflict and keep quiet if they disagree with other individuals (John \& Naumann, 2007). Many times, introverts prefer to do things alone or with one or two other people. They generally take their time making decision so that all angles have been examined before they act. However, there is a downside to this thought process; too much time is spent contemplating their decision to the point where it is too late to take action (Myers-Briggs.org) Agreeableness

The second factor, Agreeableness (II), reflects individual differences in levels of trustworthiness and cooperative behavior. Individuals who score high in Agreeableness are goodnatured and value camaraderie. They are helpful, friendly, considerate, believe people are, on the whole, honest and trustworthy. They are also inclined to compromise in order to avoid conflict. These traits enable individuals who score high in Agreeableness to work well in group settings. However, they generally find it difficult to make tough or objective decisions. Individuals who 
score low on Agreeableness tend to be self-centered and, in general, not concerned with others' well-being. They are often suspicious of others' motives and can be uncooperative. In addition, individuals who score low in Agreeableness have been known to suffer from cardiovascular disease, interpersonal problems, and juvenile delinquency (John \& Naumann, 2007).

\section{Conscientiousness}

Factor III, Conscientiousness, describes how individuals control impulse reactions to the environment, such as thinking before doing or following rules. Those individuals scoring high on Conscientiousness tend to arrive to their destinations or appointments early or on time, plan ahead, are organized, and prioritize tasks. As students, they are generally the ones who repeatedly check their papers for errors, arrive to class early and prepared, and study hard to ensure they earn the highest grade in the class (John \& Naumann, 2007; John \& Srivastava, 1999). Conscientious individuals are generally healthier as they follow treatment regimens, and as a result, live longer (John, Naumann, \& Soto, 2008). Individuals scoring low in Conscientiousness are generally unorganized and have issues planning and prioritizing tasks. They tend to make impulse decisions without thinking through the consequences and tidiness is not high on their list of priorities (John \& Srivastava, 1999). These individuals are also prone to substance abuse, lack good diet and exercise habits, and have higher occurrences of attentiondeficit/hyperactivity disorder (ADHD) (John, Naumann, \& Soto, 2008).

\section{Neuroticism}

Neuroticism, factor IV, is a reverse-keyed category. Items in this category are phrased in such a way that an agreement with the item reflects a low level of the characteristic being measured, which in this case, is emotional stability. Individuals scoring high in Neuroticism have strong feelings of anxiety, sadness, and nervousness (John \& Srivastava, 1999). Their emotional 
responses are more intense, they react strongly to situations which would not perturb most people, and become distressed when conflict arises (John \& Naumann, 2007). High scores in Neuroticism have been linked to poor coping and decision making skills, frequent job changes, and the inability to let go of emotional baggage. On the other end of the scale, those scoring low in Neuroticism are more even-tempered and emotionally stable. They are more likely to be optimistic than pessimistic and do not dwell on negative feelings.

\section{Openness to Experience}

The last factor, Openness to Experience (V), measures an individual's mental and experiential life, as well as describes cognitive style. It also measures individual differences in imagination and creativity; what differentiates artistic and creative people from more pragmatic, conventional individuals (John, Naumann, \& Soto, 2008). Individuals who score high in Openness are intellectually curious, explore new topics just for the joy of learning, search for stimulating ventures to break the monotony of everyday life, and are appreciative of art and beauty. These individuals also tend to perform well on creativity tests.

Interestingly, measured intelligence is modestly related to Openness to Experience and Conscientiousness and can be attributed to either or both factors (McCrae \& Costa, 1977). Openness to Experience traits such as being imaginative, inventive, and intellectually curious, and Conscientiousness traits such as being efficient, well-organized and competent have been associated with intelligence. Personality traits have also been linked to academic achievement. For example, Conscientiousness scores have been associated with GPA (Conrad, 2006) and performance on exams (Chamorro-Premuzic \& Furnham, 2003). Openness to Experience combined with Conscientiousness and Agreeableness can predict overall school performance (Farsides \& Woodfield, 2003; Poropat, 2009). 


\section{Personality Stability}

Stability of personality is a topic met with much controversy among researchers and clinicians. A person's habits, skills, relationships, roles and attitudes are motivated by external influences and primary tendencies (McCrae \& Costa, 2008). Characteristic adaptions help individuals assimilate into their continuously changing social environment. To accurately evaluate the possibility of change in personality, longitudinal studies have been conducted, but few have examined personality stability. One such study examined personality of junior high students over a 30-year period (Block, 2014). Personality factors of participants were measured at three time intervals: adolescence, in their mid-30s and again in their mid-40s. The results found that personalities changed very little over 30 years. Cheerful teenagers were cheerful adults and self-defeating teenagers grew to be self-defeating adults. A similar longitudinal study by Costa concluded that, "the assertive 19-year-old is the assertive 40 -year-old is the assertive 80-year-old . . . unless something happens to change it" (Gibson \& Hodgetts, 2013, p. 60). An example of something that could affect personality is an extremely traumatic life event or developmental change. Personality in adolescents and young adults can change as a result of life experiences, events and environment. For instance, divorce or the loss of a family member through death has the capacity to change personality (Prevoo \& TerWeel, 2014).

Changes in personality have been associated with musical experiences. For instance, results of research reveal that a music educator's personality can change over the course of his or her career (Steele \& Young, 2011). Pre-service music educators scored higher on Perceiving while experienced music educators scored higher on Judging on the MBTI. These are the two orientations that describe an individual's outer life; the behaviors that are observable to others (Briggs-Myers, 2016). Those whose prefer Judging seem to live a well-planned, orderly life. 
They like to have issues resolved and are more relaxed once decisions have been made. Individuals who prefer Perceiving live a more flexible and spontaneous life, they are able to adapt to change rather than fix it. However, in their inner world, they may be well-planned and organized. There were similar findings reported for music therapists as a function of experience. While we cannot directly attribute changes in personality to musical experience, we surmise that changes may be due to the nurturing environment necessary for positive musical experiences. Personality, Cognitive Style, and Learning Styles

The relationship between personality, cognitive style, and learning styles has been of great interest to researchers. Cognitive style pertains to the preferred manner in which an individual processes (i.e., perceives, organizes, and analyzes) information through cognitive brain-based structures, and is linked to a person' cognitive system (Armstrong, Peterson, \& Raynor, 2011). These structures or mechanisms may be innate preferences which are relatively stable and partly fixed. Learning style refers to an individual's preferred manner of responding, either behaviorally or cognitively, to learning tasks. How an individual chooses to respond may change based on the context or environment, thus making their learning style adaptable.

Studies have shown that personality greatly influences cognitive style, learning style (Komarraju, Karau, Schmeck, \& Avdic, 2011), achievement motivation, and academic performance (Busato, Prins, Elshout, \& Hamaker, 1999; Chamorro-Premuzic \& Furnham, 2003 \& 2008; Chamorro-Premuzic, Furnham, \& Lewis, 2007; Corrigall, Schellenberg, \& Misura, 2013; Duff, Boyle, Dunleavy \& Ferguson, 2003; Furnham, 1992; Jackson \& Lawty-Jones, 1996; Komarraju, Karau, Schmeck, \& Avdic, 2011). Certain personality traits have been positively linked to academic success whereas others have been negatively linked: Openness to Experience and Conscientiousness have been positively linked, whereas Neuroticism has been negatively 
linked (Chamorro-Premuzic, Furnham, \& Lewis, 2007; Corrigall, Schellenberg, \& Misura, 2013;

Komarraju, Karau, Schmeck, \& Avdic, 2011). Individuals who score high in Openness to Experience tend to be academically inquisitive and prefer reflective learning styles (e.g., complicated processes and synthesis-analysis) (Komarraju, Karau, Schmeck, \& Avdic, 2011). Individuals who score high in Conscientiousness tend to be self-disciplined, achievement-driven and tend to prefer methodical study habits.

Furnham's (1992) study utilizing the Eysenck Personality Questionnaire [EPQ (Eysenck \& Eysenck, 1997)] and the Learning Styles Questionnaire [SLQ (Honey \& Mumford, 1992)], found different personalities use different decision making strategies and have different cognitive styles. The EPQ measures and categorizes personality into three broad characteristics:

Extroversion (E), Neuroticism (N), and Psychoticism (P). The LSQ is based on Kolb's learning cycle (Concrete Experience, Reflective Experience, Abstract Conceptualization, and Active Experimentation) and measures an individual's preferred learning style (Kolb, 1984). Each category in the learning cycle is given a descriptor: Activist (A), Theorist (T), Reflector (R), and Pragmatist (Pr). Furnham's (1992) results showed that individuals who scored high on Extroversion also scored high in Pragmatist and Activist, and those who scored low on Extroversion scored high in Reflector. These differences not only affect how individuals learn, but may also may influence choice of academic major in college or career choice.

\section{Personality Traits of Creative People}

Are there certain personality traits that separate creative people from the norm? The personality traits of creative individuals have long intrigued researchers, and it is these traits that differentiate exceptionally creative people from the general population. Researchers have 
examined the common traits among musicians, visual artists, dancers and other creative types (Abudamde \& Csikszentmihalyi, 2004; Baltzer, 1988; Csikszentmihalyi \& Gestzels, 1973; Kemp, 1981a, 1981b, 1981c, 1982c, 1996; Marchant-Haycox \& Wilson, 1992), while others have examined the personality differences of college students majoring in the arts as compared to those who are non-arts majors (i.e., Physical and Biological Sciences, Business, etc.) (Kaufman, Pumaccahua \& Holt, 2013). Previous studies have shown that creative people, in general, share unique traits (Cross, Cattell, \& Butcher, 1967; Csikszentmihalyi \& Getzels, 1976; Drevdahl \& Cattell, 1958; Gelade, 2002). Csikszentmihalyi, who has spent his career studying the work habits and lives of creative people, has found common traits among creative people. In his book, Creativity: The Work and Lives of 91 Eminent People (HarperCollins, 1996), Csikszentmihalyi outlines ten contradictory traits commonly found in creative people that are assimilated into opposing forces. For example, creative people have a tendency to be both introverted and extroverted, are impassioned by and critical of their own work, and can be self-effacing and arrogant at the same time. Many creative people tend to be quite intelligent, but also seem naïve, and alternate easily between fantasy and reality. However, the most common trait, and most likely the most important, is the ability to enjoy the creative process itself: art for art's sake.

In an earlier longitudinal study, Csikszentmihalyi and Getzels (1976) followed the careers of 281 art students at the Art Institute of Chicago to identify personality traits of successful artists. Twenty years later, participants who were the most successful artists shared traits most commonly found in Wall Street marketing executives than their fellow artists; they were more social, practical and career oriented. Thus, differences in creative personalities can influence both career path and decisions to participate in group activities such as musical ensembles. As compared to the general population, creative people tend to be more introverted, self-sufficient 
and intelligent (MacClellan, 2011). These would be valuable traits for musicians in particular, as hours are spent in individual practice.

Marchant-Haycox \& Wilson's 1992 study compared the personality types of music, dance and drama students, as well as professional performers. The 162 performing artists/students (56 musicians, 38 singers, 33 actors, and 26 dancers) were recruited from music, ballet, and drama colleges, the London Symphony Orchestra, the English National Opera, and the Royal Opera House (Covenant Garden). The control group (supplied by Corporate Assessment, Ltd.) consisted of 500 males and 300 females whose mean age of 34.2 (SD 11.5), was commensurate to that of the performing artists/students. Participants were given two measures: (1) The Eysenck Personality Profiler (EPP) (Eysenck \& Wilson, 1991), and (2) the Health Survey Questionnaire (HSQ). The EPP is a multi-trait personality test containing 440 items and arranged into 21 "primary" bipolar traits, which are divided among three major dimensions: Extroversion/Introversion, Emotionality, and Adventurousness. The EPP also includes a Dissimulation or "Lie" scale. The HSQ was a custom-made self-report inventory consisting of basic demographic data, as well as questions regarding stress-related symptoms such as performance anxiety, back pain, drinking and smoking habits, and migraines. The results showed that dancers were the most emotional, exhibited high anxiety, were prone to hypochondria, and scored low in self-esteem. Thirty-eight percent of the dancers reported bouts of depression, which previous research findings attribute to the qualities and unusual stresses demanded by the dance profession. Actors and drama students tended to be the most extroverted and expressive. The musicians (instrumentalists) were predominantly introverted and unadventurous. The vocalists scored between the actors/drama students and instrumentalists on the majority of the attributes. 
Creativity is an essential trait for any artist, whether it is visual art, music, architecture, dance or science. Personality traits such as Openness to Experience, Agreeableness, level of Extroversion and Conscientiousness have all been linked to trait creativity ( $\mathrm{Li}, \mathrm{Li}, \mathrm{Huang}$, Kong, Yang, et al., 2014). Only Openness to Experience moderated the relationship between the right posterior middle temporal gyrus (pMTG), the area of the brain known for processing sounds and trait creativity.

This was discovered through a recent study conducted at the Beijing Normal University (China). The participants were 252 healthy college students (114 males and 138) between the ages of 18 and 25 years. Each participant was administered three assessments measuring trait creativity, personality, and intelligence. Trait creativity was measured by the Chinese version of the Williams Creativity Aptitude Test (WCAT) (1980). This self-report assessment contains 50 items and measures risk-taking, curiosity, and imagination using a six-point Likert scale. Behavioral results from the total score of the WCAT revealed a relationship to three personality domains: Openness to Experience, Conscientiousness, and Extroversion.

Personality was assessed utilizing the Revised NEO Personality Inventory (NEO-PI-R; Costa \& McCrae, 1992), a 120-item self-report questionnaire based on five factor model of personality. To measure general intelligence, researchers utilized Raven's Advanced Progressive Matrix (RAPM; Raven, 1998). The scale consists of 26 non-verbal items, each item requiring the participant to complete a $3 \times 3$ matrix by selecting the missing piece from eight alternatives. Participants were then scanned utilizing a Siemens 3T scanner (MAGENTOM Trio, a Tim System) and structural magnetic resonance images (sMRI) were captured. In order to identify the brain regions underlying individual differences in trait creativity researchers used Using voxelbased morphometry (VBM). VBM is a neuroimaging technology that permits examination of the 
main differences in brain anatomy by recording each brain to a template and discarding large differences of brain anatomy of subjects. Brain images are then smoothed so that each voxel represents the average of itself and contrasted across brains on every voxel. Trough VBM, researchers discovered higher grey matter volume in the right pMTG of creative individuals. Agreeableness, Conscientiousness, Extroversion, and Openness to Experience all contributed to trait creativity; however, only Openness to Experience mediated the relationship between creativity and the right pMTG. Results suggest that an individual's creativity may be influenced by Openness to Experience.

\section{Personality Traits of Musicians}

There have been several studies examining the personalities of musicians from different perspectives (i.e., by gender, instrument, as compared to population norms, etc.). Kemp's series of studies examined personality differences in high school, collegiate and professional musicians based on musical experience. The participants for the college sample (which Kemp referred to as the "student" sample) of the study were full-time music students ( $n=688)$, ages 18 - 25 years, recruited from 20 British conservatories and universities. A comparison sample of 120 college students was chosen based on age, socioeconomic status and educational level. Students with creative or musical interests were removed from the comparison sample. All participants completed Cattell's 16 Personality Factor Questionnaire (16PF), forms A and B. The raw scores from both the musician group and non-musician group were separately examined by a Multivariate Analysis of Covariance (MANCOVA). The college musicians were characterized by introversion, pathemia, anxiety, intelligence, and good upbringing (Kemp, 1981b). Good upbringing was measured by two traits in Kemp's study: Rule Consciousness and Perfectionism. Individuals scoring high in Rule Conscious tend to be principled, morally grounded, and 
conform to social norms. Those scoring low tend to be self-indulgent and have total disregard for others. Individuals scoring high in Perfectionism tend to be self-disciplined, organized, and exhibit self-control, whereas low scorers tend to lack self-discipline are unorganized, and show disregard for social rules.

The professional musicians were administered the same assessment tools and compared to samples of British norms or non-musicians. The professional musicians were characterized by introversion, anxiety, pathemia, intelligence, naturalness, and subjectivity. Based on results, Kemp proposes that musicians are able to fully focus on technical music skills and withdraw into an imaginative mental state simultaneously.

Lanning's (1990) study of 607 music majors from seven Oklahoma universities examined personality differences from several angles. Among those topics researched, personality differences between vocalists and instrumentalists, differences between concentrations within music, i.e., music education, music business, performance, etc., and differences in personality by gender were analyzed. Utilizing the Myers-Briggs Type Indicator (MBTI), Lanning used type tables to report findings by gender and category, with a comparison to normative samples from the Center for the Application of Psychological Type for college-age males and females. Lanning used Chi-Square analysis of type as the initial regression analysis yielded inconclusive results. The study found that both male and female vocalists preferred ESFJ (Extrovert, Sensing, Feeling, Judging) whereas female instrumentalists preferred INFJ (Introversion, Intuitive, Feeling, Judging) and males preferred INTP (Introversion, Intuitive, Thinking, Perceiving). Differences by degree concentration varied slightly by gender: females in pursuit of a Bachelor of Music degree preferred ENFJ (Extroversion, Intuitive, Feeling, Judging) and males preferred INFJ. All music education majors preferred Extroversion. This is also consistent with Kemp's (1982a) and 
Wubbenhorst's (1994) findings. The current study extended this work by evaluating personality traits of ensemble sections with a different standardized measure.

A more recent study conducted by Reardon (2009) examined the personality types of 355 high school musicians enrolled in band, chorus, and/or orchestra. Utilizing the MBTI, Reardon ascertained the personality type for each participant then calculate the frequencies for each dichotomy. The results showed that the most preferred MBTI type across ensembles was ENFP. Using four 3 X 2 independent-samples Chi-Square tests with an alpha of .05, Reardon found a significant difference in the E-I dichotomy: 59\% of band student, $54 \%$ of orchestra students, and $71 \%$ of chorus students preferring Extroversion (E). There were no significant differences found between ensembles for the other three dichotomies. Using Chi-Square goodness-of-fit test, individual ensembles were compared to MBTI norms for high school students. Results found that when compared to high school norms, chorus students were significantly more Extroverted (E), Intuitive (I), and Feeling (F). Band students were significantly more Intuitive (N), Feeling (F), and Perceiving $(\mathrm{P})$, and orchestra students were more Intuitive $(\mathrm{N})$ and Feeling $(\mathrm{F})$. These findings support the previous studies of Kemp (1981a) and Buttsworth and Smith (1995). This could suggest that traits linked with Intuitive and Feeling are indicative of high school ensemble musicians.

Personality traits measured in high school musicians, music educators, and music therapists, reveal common traits including Intuitive/Feeling (N-F) dichotomies as measured by the MBTI (Reardon, 2009; Steele \& Young, 2011; Wubbenhorst, 1994). Steele and Young's (2011) study examined the personality traits of professional music therapists and music educators. The researchers then compared the traits to those of college students majoring in those two disciplines as well as the personal characteristics proposed by the National Association for 
Music Education (NAfME) [formerly known as The Music Educators National Conference (MENC)] and the American Music Therapy Association (AMTA). The participants were a voluntary convenience sample of 253 professional certified music educators $(n=110)$ and music therapists $(n=143)$. Utilizing the MBTI, researchers found that professional music educators preferred ENFJ and the professional music therapists preferred INFJ. This is in contrast to their previous (2008) findings for 382 college students majoring in music education $(n=170)$ and music therapy $(n=207)$. ENFP what the highest frequency distribution for both majors, music education ( $n=56)$ and music therapy $(n=52)$. The second most frequent among music education majors was $\operatorname{ENFJ}(n=33)$, while the second most frequent type for music therapy was almost evenly distributed between INFJ $(n=29), \operatorname{ENFJ}(n=28)$, and INFP $(n=27)$.

Intuitive/Feeling individuals tend to rely on their instincts, are considerate of others in their decision-making and are subjective of emotional situations (Myers, 1985). The NFJ combination characterizes individuals who want to help people and generally have careers filling that capacity (i.e., counseling, religion or the arts).

While there are several studies investigating the personalities of student and professional musicians, few focus on community ensembles. These ensembles primarily consist of nonprofessional or semi-professional musicians who continue to perform after formal training (i.e., high school or college band, orchestra, or chorus). A recent study by Wellborn (2012) examined the personality types of adults participating in community bands in the North Georgia area. The sample included participants from five ensembles with a potential participant pool of 365 . The overall response rate was above average at $51 \%(n=186)$. The participant sample was quite diverse in terms of age, musical experience, years playing the instrument, education, and occupational background. Each participant was administered the MBTI and the researcher 
designed Adult Band Participation Preference survey (ABPPS), which collected data in regards to music participation preferences. To compare personality types and function pairs to a larger, general pool, the National Representative Sample (NRS) was utilized. Also, the participant function pair preferences were analyzed for internal comparison within the sample itself.

Wellborn found the most common MBTI function pair preference to be Sensing/Thinking (S/T), with Intuitive/Feeling (N/F) and Intuitive/Thinking (N/T) the next two most common. The modal type of the sample was ISTJ. This is in contradiction to previous studies by Reardon (2009) and Wubbenhorst (1994) which found Intuitive/Felling (N/F) to be the most common function pair among their samples. The two most common MBTI attitudes found were Introverted Judging (I/J) and Extroverted Judging (E/J), which confirms earlier studies. Interestingly, there was no correlation between being classified as N/F and having majored in music or having worked in the music field, nor was there a connection between MBTI function pair preference and reasons for participating in an adult community band.

A more recent study conducted by Vaag, Sund, and Bjerkeset (2017) examined the personality traits of 1,600 members of the Norwegian Musicians' Union and 6,372 individuals of the Norwegian workforce, utilizing the Big Five Inventory (BFI-20). Their findings showed higher degrees of Openness to Experience and Neuroticism in musicians as compared to the general workforce. Interestingly, musicians who were full-time freelance musicians scored higher in Openness to Experience than freelance musicians who were employed outside the music profession. Their findings also differed by in instrument group; vocalists scored higher in Openness to Experience, while strings players scored higher in Introversion and Neuroticism. 


\section{Personality Type and Musical Instrument Choice}

Many factors contribute to instrument selection. An instrumentalist may take into consideration the size of the instrument. A band director may suggest a certain instrument based on embouchure. There are long-standing myths associating the personality types of musicians with their choice of primary instrument (i.e., brass players are loud and obnoxious whereas violinists are slightly neurotic and temperamental). In recent history, there has been a more scientific approach to the study of musicians' personalities in the form of personality assessment tools (i.e., 16PF, NEO-PI-R, MBTI) (Gibbons, 1990; Hyden, 1979; Kemp, 1981a, 1981b, 1982a, 1982b; Langendörfer, 2008; Lanning, 1990; MacClellan, 2011; Marchant-Haycox, \& Wilson, 1992; Payne, 2009; Steele \& Young, 2011; Young, 2001). There has also been a considerable amount of evidence found supporting a correlation between personality and instrument choice (Bell \& Cresswell, 1984; Builione \& Lipton, 1983; Buttsworth \& Smith, 1995; Cameron, Duffy

\& Glenwright, 2014; Hyden, 1979; Chang, 2007; Kemp, 1981b; Lipton, 1987). Some studies had similar results: brass players were found to be extroverted, aggressive, and lacked sensitivity (Davies, 1978; Heil, 1959). However, other studies found differing results from previous studies. For instance, Kemp (1971) and Martin (1976) found introversion to be the most important trait among string players, whereas Davies (1978) regarded anxiety to be the most important trait.

Although there has been rigorous research regarding personality traits of musicians, only a handful of studies evaluated personality traits in collegiate musicians (Kemp, 1981a, 1981b, 1982a, 1982b; Lanning, 1990; Steele \& Young, 2011; Young, 2001). Hyden's (1979) study of 291 undergraduates examined the relationship between personality characteristics, instrument preference and musical style preference. Participants were recruited from four universities in Texas: $46 \%$ male, $54 \%$ female, $25 \%$ had two years or less of musical training, $38 \%$ had more 
than two years training, and $37 \%$ had no musical training. Hyden utilized Cattell's $16 \mathrm{PF}$ and two researcher-constructed surveys: The Musical Style Preference Test and the Musical Instrument Preference Test. The Musical Style Preference Test had a test-retest reliability range of .60 - .89 and the Musical Instrument Preference Test had a test-retest reliability range of .74- .90 . Hyden found numerous correlations: 38 of the 144 coefficients assessing the relationship between preferences for musical style and personality were significant beyond the .05 level, and 41 of the 192 coefficients assessing the relationship between preference for musical instruments and personality were significant beyond the .05 level. The most popular instrument, piano, was preferred by individuals whose personalities were describes as active, care-free, impulsive, creative, intelligent, and cheerful. Individuals who preferred drums were tough-minded, shy, worrisome, and moody. Violinists were characterized as intellectual, critical, and experimenting. Individuals who preferred the violin and saxophone were analytical, more intelligent, and had higher abstract reasoning skills. The trumpet was preferred by individuals who were practical, detail oriented, and concerned with doing what is right. Individuals who preferred the string bass, the least preferred instrument, were characterized practical, realistic, and responsible, but may be somewhat lower than average in intelligence.

Significant differences between and within sections of the ensembles were also found. Kemp's (1982a) study confirmed earlier findings: strings were found to be the most introverted and aloof, with cellists scoring highest on aloofness, and violists were found to be the most emotionally stable. Woodwind players tended to show high levels of shyness and selfsufficiency, which are linked to Introversion, with a strong second order factor of radicalism. Flutists, specifically, showed high levels of imagination. Brass players showed low levels of sensitivity and intelligence and high levels of surgency and group dependence. It should be noted 
that while the traits of lower intelligence, sensitivity and imagination are used to describe the professional brass player, it is made in comparison with other professional musicians. However, it does not hold true when compared to the general population. This is in contradiction to musicians in other sections who scored closer to the opposite end of the trait poles in sensitivity and intelligence. Kemp also did not find an overall trend towards Extroversion in brass players, as was found in previous studies (Martin, 1976). Personality traits for keyboard players included Extroversion, Adjustment, Good Upbringing, Conservatism, and Submissiveness. Vocalists were the most extroverted and sensitive of all musicians sampled, and showed evidence of independence.

Others have argued there is no association between instrument choice and personality. Cutietta and McAllister (1997) found no variance in personality traits in band and orchestra students in grades 7-12, compared to the general middle and/or high school population. Also, no differences were found in personality type as a result of the student's grade and instrument choice. The population for this study included students from eight schools in urban, suburban, and rural areas. The researchers also chose ensemble directors with differing teaching styles in order to reduce the effect of teacher personality on the results. Participants were administered the Junior Eysenck Personality Questionnaire (JEPQ) (Eysenck, 1975) to measure four personality traits: Extroversion, Emotionality, Tough-mindedness, and Lying. When compared to the Big Five, Extroversion and Emotionality are the equivalent to Extroversion and Neuroticism, respectively. Individuals scoring low Though-mindedness are warm and caring, whereas those who score high are generally not well socialized, lack compassion for others, and can be hostile and/or aggressive (Eysenck \& Eysenck, 1975). Lying measures the propensity of the participants to inflate or exaggerate their answers to make themselves "look good" on the inventory; they 
worry about how others view them. Those who score low on Lying would not falsify their answers to appear better in the eyes of their peers. As stated previously, the personalities of the student musicians did not differ from the general population. However, two of the characteristics, Tough-mindedness and Lying, became more homogeneous among instrumentalists across grade levels.

Another factor in instrument selection is timbre. A recent study found that certain personality types preferred certain timbres (Payne, 2009). In his study of $5^{\text {th }}-12^{\text {th }}$ grade students $(n=624)$, Payne found that individuals who scored high in Openness were more likely to prefer woodwind instruments over brass instruments based on timbre preference. Conversely, those individuals who scored higher on extroversion were more inclined to prefer brass instruments over woodwinds instruments, based on timbre preference. This supports previous findings that brass players tend to be more extroverted than woodwind players (Kemp, 1981a; Reardon, 2009; Wubbenhorst, 1991).

\section{Gender and Musical Instrument Choice}

Gender can also influence personality traits, which, in turn, can affect instrument choice. Kemp (1982) found three major factors - outgoingness, surgency (quickness, cleverness) and self-sufficiency - were related to secondary factor of Extroversion and Introversion. Female musicians deviated more from the non-musician females than male musicians deviated from the non-musician males. Female musicians were more aloof and self-sufficient, which supports previous findings of the significance of Introversion in the musical temperament. Cattell (1973) found no gender bias between Extroversion and Introversion as the female-related outgoingness and group dependency are countered by male ambivalence toward surgency and adventurousness. This implies that the highest levels of each of these traits are shared by both 
sexes. People who are inflexible in self-concept of gender identity may have difficulty in the profession. However, there was an indication that professional woodwind players and student brass players were able to maintain polarity in gender-related personality, retaining a stricter gender identity more closely related to general population norms.

Instruments can be viewed as gender specific and may also influence instrument choice. For instance, the flute and violin are perceived as instruments for females, whereas the trumpet and drums are viewed as choices for males. Other instruments, such as the cello and saxophone, are considered androgynous (Builione \& Lipton, 1983). Conway's (2000) study of gender and instrument choice found that some high school students made their instrument decisions based on stereotypes. For instance, one male clarinet student stated he probably would not have chosen the flute, even if he liked it, because he "knew it was really a girl thing." A few students stated that society plays a role in the decision-making process. One female student mentioned that girls are not taught that they should not play the trombone, but there is a sense that it would not be the best choice. However, some students completely disregarded the gender stereotypes attached to certain instruments. Those students discussed their need to be different from the norm, having parental support of their decision, encouragement from their elementary music teacher, and their ability to brush off negative or derogatory comments from classmates.

\section{Summary}

The purpose of this study was to examine the personalities of musicians who participate in collegiate and community ensembles. Understanding the personalities of the members of one's ensemble could be very useful when developing lesson plans, choosing repertoire, and communicating with ensemble members. For instance, previous studies have shown that choral ensemble members are more Extroverted than band and orchestral ensemble members (Reardon, 
2009). Extroverts tend to project their energy to others, making them a very social group and they enjoy verbal communication. These students learn best by doing or activity driven lessons and group work. Teachers who develop student-centered lesson plans by putting the students in a leadership position for a portion of the rehearsal may be surprised to find a different level of focus. 


\section{CHAPTER THREE}

\section{METHOD}

This descriptive research explored the personalities of individuals who choose to participate in collegiate music ensembles and those who participate in ensembles after high school and/or college. To measure personality traits a demographic questionnaire as well as the Big Five IPIP was utilized to broadly collect data electronically and via paper/pencil. All procedures and methods for this study have been approved by the University of South Florida's Institutional Review Board (IRB), and are certified as Exempt.

\section{Participants}

\section{Collegiate Participants}

Participants were undergraduate and graduate students enrolled in band, chorus, or orchestra recruited from selected universities in California, Florida, Georgia, Illinois, Mississippi, New York, South Carolina, Tennessee, and Texas. The universities were chosen for their diverse locations and enrollment size. These institutions were also chosen for convenience as the ensemble directors were known to the principal investigator. Fourteen ensemble directors were contacted and eleven agreed to participate in the study.

Participation in the study was open to both music majors and non-music majors enrolled in band, chorus, orchestra, or any other formal music ensemble offered and is completely voluntary. For independence of groups, participants were asked to choose their preferred ensemble if enrolled in more than one. The decision not to participate did not affect the students' 
grade or standing in any manner. Because this study investigated the personalities of musicians; majorettes, dancers and other auxiliary marching band members were not included. Snowball sampling was used to recruit non-musician collegiate participants.

\section{Community Participants}

Participants were musicians participating in community band, chorus or orchestra recruited from metropolitan in Connecticut, Florida, Georgia, Massachusetts, New Jersey, New York, South Carolina, Tennessee, and Texas. Ensembles were chosen for their location as well as convenience as the conductors were known to the primary investigator. Nine ensemble directors were contacted and all nine agreed to participate in the study. Participation in the study was open to all musicians in the selected ensembles. As per the previous sample, majorettes, dancers and other auxiliary marching band members were not included. Snowball sampling was used to recruit non-musician community participants.

\section{Procedures}

The ensemble directors chosen to participate in the study were known to the principle investigator and were contacted for permission. After initial contact, a brief explanation of the study was sent to ensemble directors. After permission was granted, a cover letter and link to the Informed Consent, demographic survey and the Big Five Personality Inventory IPIP was sent to the director for mass distribution either through email or on their closed social media site.

Participants enrolled in more than one ensemble were asked to select a preferred ensemble to answer the questions regarding ensemble participation. 


\section{Demographic Survey}

Collegiate participants responded to seventeen demographic questions (See APPENDIX B) and the Big Five Personality Inventory (Goldberg's IPIP), which is based on the Five Factor Theory (FFT). The Community ensemble participants responded to thirteen demographic questions (See APPENDIX C) and the Big Five Personality Inventory (Goldberg's IPIP).

\section{Personality Measurement Instrument}

Big Five Personality Inventory. The Big Five 50-item IPIP (See APPENDIX D) representation of the Goldberg (1992) markers for the Big-Five factor structure was chosen to measure the personality traits of participants. The inventory measures the personality dimensions of Extroversion, Agreeableness, Conscientiousness, Neuroticism, and Openness to Experience. Each trait is measured by 10 questions. Each question has a Likert scale of 1-5 ( $1=$ "Strongly Disagree," 2 = "Somewhat Disagree," 3 = "Neutral," 4 = Somewhat Agree, and 5 = "Strongly Agree"). Extroversion traits are interpreted as excitement seeking, gregariousness, and warmth. Agreeableness refers to traits of likability, such as being good-natured, forgiving and trustworthy. Conscientiousness refers to traits such as dependability, acting responsibly and being organized. Neuroticism measures levels of anxiety, self-consciousness and depression. Openness to Experience refers to artistic sensitivity, originality, and imagination (Viswesvaran \& Ones, 2000). The test-retest reliability for each trait is as follows: Extroversion $(r=.88)$, Agreeableness $(r=.80)$. Conscientiousness $(r=.77)$, Neuroticism $(r=.89)$, and Openness to Experience $(r=.79)$ (Donnellan, Oswald, Baird, et al., 2006). 
Analysis

Online data were downloaded from Qualtrics to Excel. Paper and pencil surveys were entered by hand into Excel. Using SPSS, descriptive statistics were used to analyze the demographic data, which included gender, race, ethnicity, instrument/voice range, age formal training began, years of vocal or instrumental performance, years of ensemble participation, and current ensemble participation.

The analysis was conducted based upon the proposed research questions:

- To what extent do personality traits relate to ensemble choice (instrumental, vocal, nonmusician) and gender?

A 2 (gender) x 3 (instrument choice) Multivariate Analyses of Variance (MANOVA) was conducted with the Big Five personality traits (i.e., Extroversion, Agreeableness, Conscientiousness, Neuroticism, and Openness to Experience) as Dependent Variables. There were two levels of gender (male or female) and three levels of instrument choice (instrumental, vocal, non-musician or not currently engaged in a music ensemble). The MANOVA was chosen because there were several continuous dependent variables. Due to the large population Wilkes Lambda was used to ensure a more conservative estimate.

- To what extent do personality traits (Agreeableness, Conscientiousness, Extroversion, Neuroticism, and Openness to Experience) relate to ensemble section choice (e.g., Wind, String, Soprano, Bass)?

A MANOVA was conducted with personality traits as the Dependent Variables and the Independent Variable was the nine Ensemble Sections. The five 
personality traits were Extroversion, Agreeableness, Conscientiousness, Neuroticism, and Openness to Experience. The nine Ensemble Section choices were Strings, Wind, Brass, Percussion, Piano/Keyboard, Soprano Vocalist, Alto Vocalist, Tenor Vocalist, and Bass Vocalist. The MANOVA was chosen because there were several continuous dependent variables. Due to the large population, Wilkes Lambda was used to ensure a more conservative estimate. 


\section{CHAPTER FOUR}

\section{RESULTS}

This chapter presents the analysis and results of the data collected to answer the research questions outlined in Chapter One. The research questions are restated followed by the results obtained through a series tests to determine statistical significance $(p<.025)$. Two sets of data were collected: the descriptive data regarding the study participants and the personality trait results from the Big Five IPIP (Goldberg, 1992).

The survey was distributed to college and university students across the United States. These institutions were both public and private and ranged in size from 3,800 students to over 35,000 students. Data for the community ensembles was collected from the members of large community ensembles (e.g., marching bands, concert bands, symphonic choirs, etc.) as well as from musicians involved with small, independent ensembles (e.g., Scottish pipe bands, rock bands, church choirs). The total responses received was 756 participants. Ninety-six online surveys and 52 paper/pencil surveys were not used due to incomplete data, leaving $(N=608)$ completed data sets for analysis. Chi-square goodness of fit was utilized to compare demographic data for frequency analysis.

Two multivariate analyses of variance (MANOVA) were conducted to look for differences in the Big Five IPIP personality traits by ensemble, gender, and instrument choice. Post hoc ANOVAs were inspected for significance. Assumptions of Levene's Homogeneity of Variance Test and Box's M were run to ensure homogeneous distribution. Coefficient alpha was used to determine the internal consistency of the Big Five IPIP traits. Results were as follows: 
Extroversion, $a=.90$, Agreeableness, $a=.74$, Conscientiousness, $a=.76$, Neuroticism, $a=.89$, and Openness to Experience, $a=.79$. These results are comparable to previous findings (Donnellan, Oswald, Baird, et al., 2006; Guernole \& Chernyshenko, 2005)

\section{Analysis of Descriptive Data}

The study consisted of 608 participants from across the United States. The population consisted of three groups: Instrumentalists, Vocalists, and Non-musicians. Descriptive statistics were run to examine potential differences in group demographic factors of age, age lessons commenced, years of ensemble participation, and hours practiced per week. A significant $(p<$ .05 ) difference was found in age, $F(2,606)=5.27, p=.005$, and years playing primary instrument, $F(2,424)=4.85, p=.008$. No significant difference was found in age private lessons commenced $F(2,404)=81.90, p=.58$; years of ensemble participation $F(2,425)=.43, p$ $=.65$; and hours practiced per week $F(2,386)=.75, p=.47$. Although the population was racially and ethnically diverse, many respondents were White/Caucasian $(n=439,72.1 \%)$ and female ( $n=401,65.8 \%$ ) (See Table 1). The age range of respondents was 18 years of age to 87 years of age, with an average age of 40.28, $(S D=18.57)$ years. Age was divided into eight categories, 18-25 years to 85-94 years of age (See Table 2). For the Collegiate sample, the most frequent age range was, not surprisingly, $18-25$ year olds $(n=135)$. The average age range showing the most participants in the Community sample was the 55-64 year olds $(n=51)$, with the most frequently reoccurring age of 59 years $(n=14)$. However, there was an equal number of 49-year-olds, but not as many respondents in the 45-54-year range. Of the 180 non-musicians, the largest number of respondents were in the 18-25-year range $(n=46)$. 
Table 1

Participants by Gender and Race/Ethnicity

\begin{tabular}{lccccc}
\hline & Instrumentalist & Vocalist & Non-Musician & Total & $\%$ \\
\hline Gender & & & & & \\
Male & 90 & 74 & 41 & 205 & 33.8 \\
Female & 134 & 128 & 139 & 401 & 65.8 \\
Race/Ethnicitv & & & & & \\
White/Caucasian & 172 & 137 & 130 & 439 & 72.1 \\
Black/African Am & 5 & 4 & 4 & 13 & 2.1 \\
Latino/Hisbanic & 19 & 25 & 5 & 49 & 8.2 \\
Asian/Pacific Is & 6 & 15 & 3 & 24 & 3.9 \\
Mid-Eastern & 12 & 12 & 27 & 51 & 8.4 \\
Multi-Racial & 10 & 9 & 8 & 27 & 4.4 \\
Other & 2 & 0 & 3 & 5 & 0.8 \\
Total & 226 & 202 & 180 & 608 & 100.0 \\
\hline
\end{tabular}

Table 2

Participants by Age and Current Ensemble Participation

\begin{tabular}{lccccc}
\hline Age Range & Collegiate & Community & Other & Non-musician & Total \\
\hline $18-25$ & 135 & 15 & 6 & 46 & 202 \\
$26-35$ & 13 & 24 & 13 & 35 & 85 \\
$36-45$ & 5 & 16 & 18 & 32 & 71 \\
$46-55$ & 2 & 30 & 23 & 36 & 91 \\
$56-65$ & 3 & 51 & 18 & 26 & 98 \\
$66-75$ & 2 & 33 & 10 & 4 & 49 \\
$76-85$ & 0 & 7 & 2 & 1 & 10 \\
$86-95$ & 0 & 1 & 1 & 0 & 2 \\
Total & 160 & 177 & 91 & 180 & 608 \\
\hline
\end{tabular}

Years of Education

A cross-tabulation showed the most frequently occurring educational degree among participants was an Associate's degree $(n=154,31.88 \%)$, followed by a Bachelor's degree 
$(n=102,21.95 \%)$. Only a few $(n=8,1.66 \%)$ reported having a high school education or General Education Diploma (GED) as their highest level of education. Some participants chose not to report their years of education $(n=125,20.56 \%)$. The results are reported in Table 3 below.

Table 3

Cross-tabulation of Years of Education by Ensemble

Current Ensemble Participation

\begin{tabular}{lcccccc} 
& Collegiate & Community & Other & $\begin{array}{c}\text { Non- } \\
\text { musician }\end{array}$ & Total & $\%$ \\
\hline $\begin{array}{l}\text { High School/ } \\
\text { GED }\end{array}$ & 0 & 4 & 1 & 3 & 8 & 1.66 \\
Some College & 91 & 14 & 13 & 12 & 130 & 26.91 \\
Associate's & 0 & 60 & 28 & 66 & 154 & 31.88 \\
Bachelor's & 8 & 43 & 27 & 28 & 106 & 21.95 \\
$\begin{array}{l}\text { Master's } \\
\text { PhD/MD or }\end{array}$ & 9 & 27 & 9 & 18 & 63 & 13.04 \\
equivalent & 1 & 14 & 4 & 3 & 22 & 4.55 \\
Total & 109 & 162 & 82 & 130 & 483 & 100.00 \\
\hline
\end{tabular}

Analyses of Personality of Study Population

Research Question One

To what extent do personality traits relate to ensemble choice (instrumental versus vocal) and gender?

A 2 (gender) x 3 (instrument choice) MANOVA was conducted with the Big Five personality traits (i.e., Extroversion, Agreeableness, Conscientiousness, Neuroticism, and Openness to Experience) as Dependent Variables. There were two levels of gender (male or 
female) and three levels of instrument choice (instrumental, vocal, non-musician or not currently engaged in a music ensemble). The Box's M value $(93.308, p=.102)$ was not significant, showing the distribution of personality traits across comparison groups, gender and instrument choice (vocal or instrumental) were similar. The assumption of homogeneity was met to proceed to the analysis. The Bonferroni correction was used to avoid Type I error (i.e., alpha level set at $.05 / 2=.025$ for two separate MANOVAs in the study). Using an alpha level of .025 , multivariate tests found a significant main effect for both gender, $\Lambda=.918, F(5,596)=10.654$, $p<.001$, and instrument choice $\Lambda=.958, F(10,1192)=2.599, p=.004$. Table 4 displays the means, standard deviation, skewness, and kurtosis for Personality Traits, Instrumentalists, and Vocalists.

Table 4

Means, Standard Deviation, Skewness, and Kurtosis for Personality Traits, Instrumentalists and Vocalists

Big Five Personality Traits

\begin{tabular}{lccccc}
\cline { 2 - 5 } Instrumental or Vocal & Extro & Agree & Consc & Neuro & Open \\
\hline $\begin{array}{l}\text { Instrumentalists }(N= \\
\text { 224) }\end{array}$ & & & & & \\
$\quad$ Mean & 21.80 & 29.51 & 26.53 & 21.01 & 30.70 \\
$\quad$ Std. Deviation & 9.197 & 5.921 & 6.022 & 8.149 & 5.693 \\
$\quad$ Kurtosis & -.717 & 1.929 & -.557 & -.784 & .621 \\
$\quad$ Skewness & -.220 & -1.261 & -.307 & -.099 & -.714 \\
Vocalists $(N=202)$ & & & & & \\
$\quad$ Mean & 24.20 & 30.89 & 26.54 & 19.94 & 31.94 \\
Std. Deviation & 8.269 & 5.683 & 6.430 & 8.133 & 5.495 \\
$\quad$ Kurtosis & -.420 & 1.856 & -.168 & -.674 & -.303 \\
$\quad$ Skewness & -.202 & -1.137 & -.432 & -.137 & -.489
\end{tabular}


Table 4 Continued

Non-musicians $(N=180)$

Mean

29.93

25.21

19.56

30.58

Std. Deviation

8.952

5.513

6.259

7.979

5.457

Kurtosis

$-.723$

1.688

$-.291$

$-.703$

$-.452$

Skewness

.223

$-1.176$

$-.211$

$-.023$

$-.420$

Total $(N=608)$

Mean

22.62

30.09

26.14

20.23

31.07

Std. Deviation

8.882

5.745

6.249

8.105

5.583

Kurtosis

$-.602$

$1.816-.359$

$-.728$

.039

Skewness

$-.241$

$-1.183$

$-.320$

$-.085$

$-.551$

Analyses of the relationship between the Dependent Variables (Extroversion, Agreeableness, Conscientiousness, Neuroticism, and Openness to Experience), and Independent Variables (Gender and Instrument Choice), found statistically significant differences. Univariate tests show Agreeableness, $F(1,600)=27.79, p<.001, \eta^{2}=.044$, and Neuroticism, $F(1,600)=$ $11.99, p=.001, \eta^{2}=.020$, scores were influenced by Gender (See Figures $\left.1 \& 2\right)$. Females $(N=$ $401, M=30.98, S D=5.21)$ tended to score higher on Agreeableness than males $(N=205, M=$ 28.41, $S D=6.39)$. For Neuroticism, males $(N=205, M=22.02, S D=7.88)$ tended to score higher than females $(N=401, M=19.34, S D=8.08)$. 


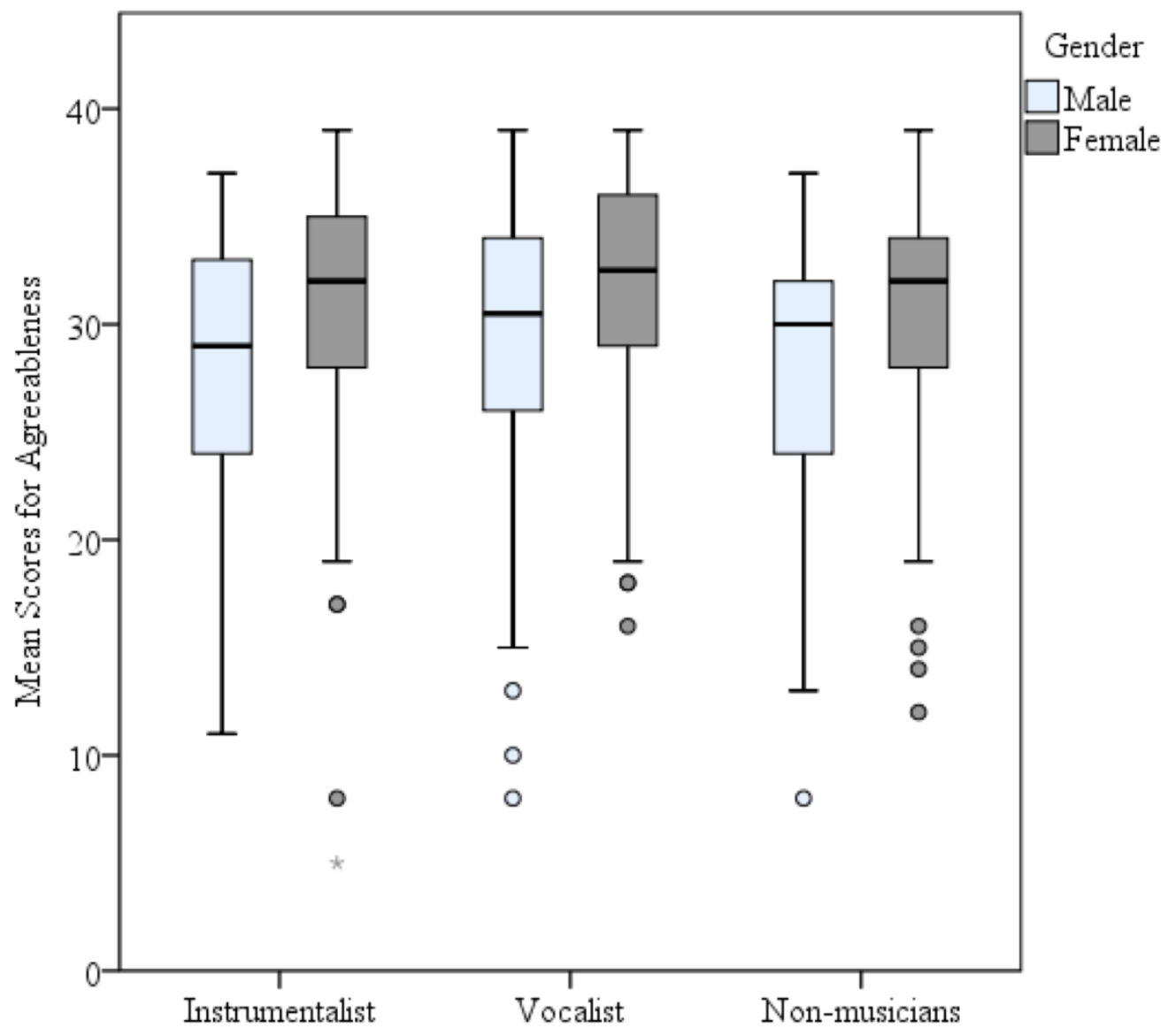

Figure 1

Graph for Agreeableness Mean Scores by Gender and Instrument Choice (Instrumentalist, Vocalist, or No Ensemble Participation) 


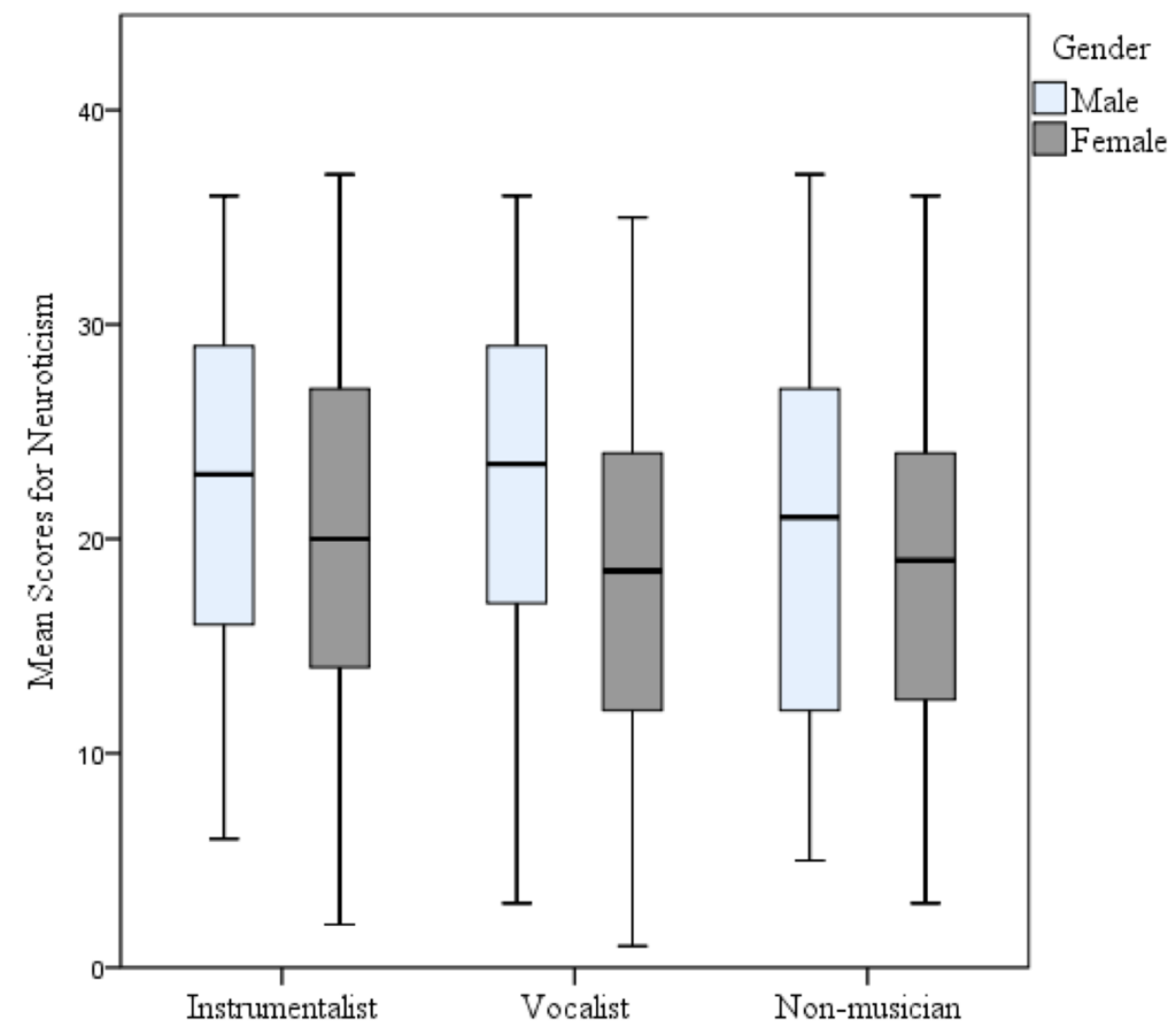

Figure 2

Graph for Neuroticism Mean Scores by Gender and Instrument Choice (Instrumentalist, Vocalist, or No Ensemble Participation)

MANOVA results also showed a statistically significant effect of personality traits Extroversion, $F(2,600)=5.36, p=.005, \eta^{2}=.018$, and Openness to Experience, $F(2,600)=$ 4.13, $p=.017, \eta^{2}=.014$ on instrument choice (vocal, instrumental, or no ensemble participation). Vocalists $(N=202, M=24.20, S D=8.27)$ tended to score higher on Extroversion than instrumentalists $(N=224, M=21.77, S D=9.23)$ and individuals not participating in music ensembles $(N=180, M=21.87, S D=8.95)$ (See Figures $3 \& 4)$. By gender, male vocalists $(N=$ $74, M=24.30, S D=8.88)$ scored the highest of the population, while males not participating in 
music ensembles $(N=41, M=20.05, S D=7.70)$ scored the lowest. For Openness to Experience, vocalists $(M=31.94, S D=5.49)$ scored higher than instrumentalists $(M=30.71, S D=5.72)$ and individuals not participating in music ensembles $(M=31.94, S D=5.49)$. By Gender, male vocalists $(M=32.74, S D=4.90)$ scored the highest, while female instrumentalists $(N=134, M=$ 30.22, $S D=5.58)$ and males not participating in music ensembles $(M=30.22, S D=5.41)$ scored similarly on Openness to Experience.

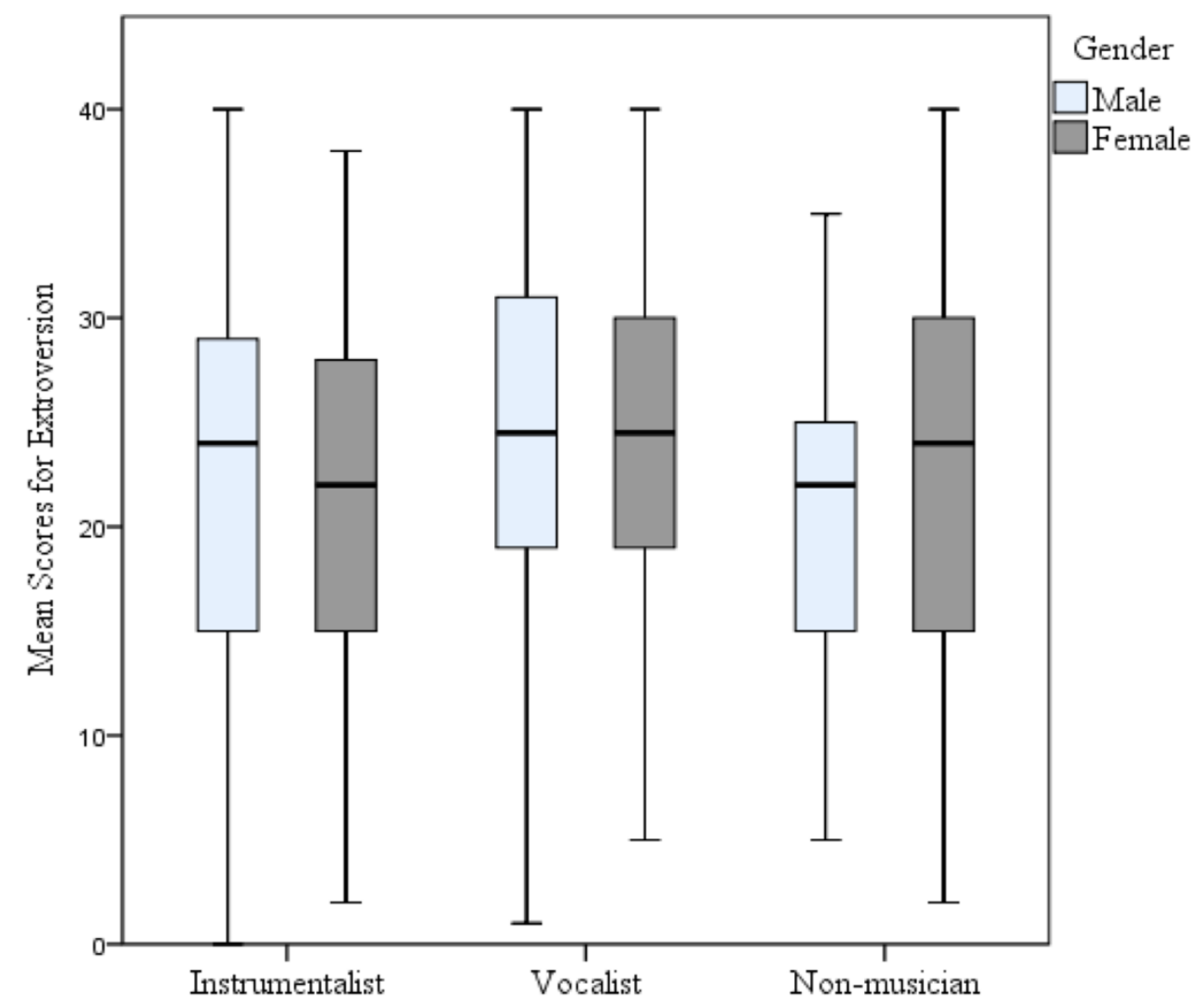

Figure 3

Graph for Extroversion Mean Scores by Gender and Instrument Choice (Instrumentalist, Vocalist, or No Ensemble Participation) 


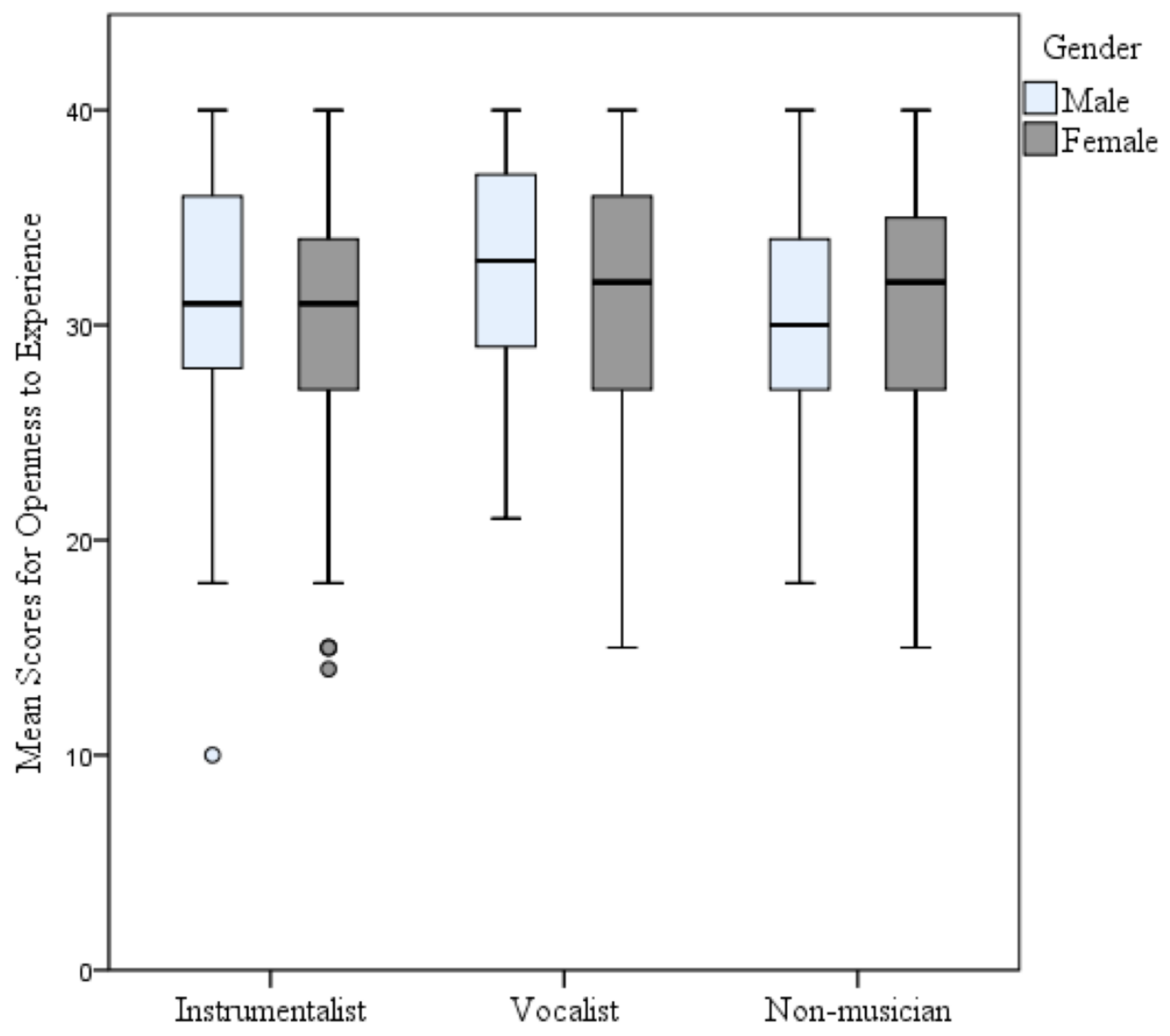

Figure 4

Graph for Openness to Experience Mean Scores by Gender and Instrument Choice (Instrumentalist, Vocalist, or No Ensemble Participation)

MANOVA results showed no significant difference for the interaction of Gender and Instrument Choice for Conscientiousness, $p=.724$. However, Instrument Choice alone was approaching significance for Conscientiousness, $F(2,600)=2.90, p=.056, \eta^{2}=.010($ See Figure 5). 


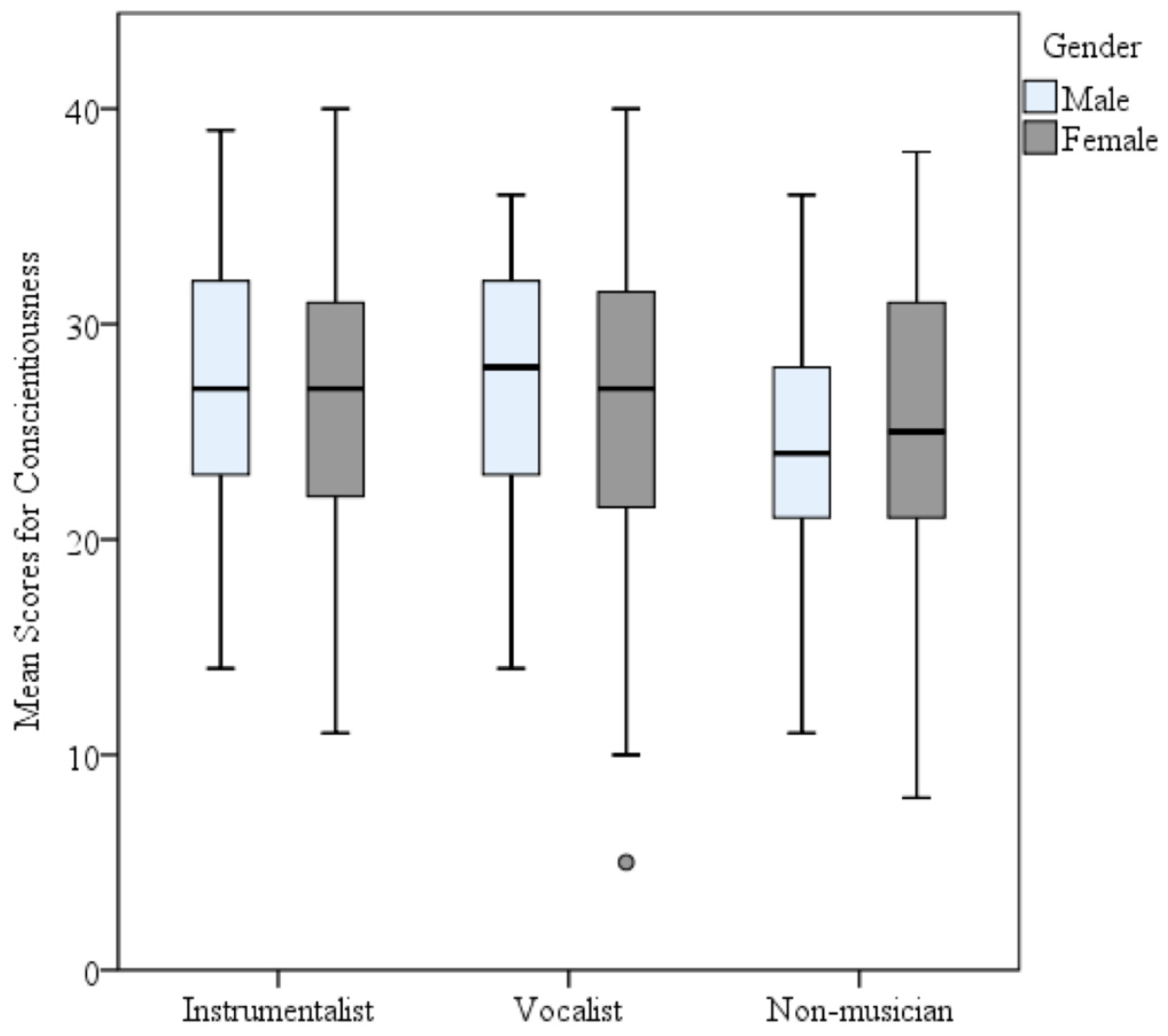

Figure 5

Graph for Conscientiousness Mean Scores by Gender and Instrument Choice (Instrumentalist, Vocalist, or No Ensemble Participation)

Research Question 2:

To what extent do personality traits (Agreeableness, Conscientiousness, Extroversion, Neuroticism, and Openness to Experience) relate to ensemble section (e.g., brass, alto voice)?

A Multivariate Analyses of Variance (MANOVA) was conducted with personality traits as the Dependent Variables and the Independent Variable was Ensemble Sections. The personality traits were Extroversion, Agreeableness, Conscientiousness, Neuroticism, and Openness to Experience. The nine Ensemble Section choices were Strings, Wind, Brass, Percussion, Piano/Keyboard, Soprano Vocalist, Alto Vocalist, Tenor Vocalist, and Bass Vocalist. 
The Box's M value (145.731, $p=.125)$ was not significant, showing the distribution of personality traits across comparison group, instrument section, were similar. The assumption of homogeneity was met to proceed to the analysis. The Bonferroni correction was used to avoid Type I error. Using an alpha level of .025, multivariate tests found a significant main effect for instrument section, $\Lambda=.824, F(40,1803)=2.052, p<.001$. Table 5 displays the means, standard deviation, skewness and kurtosis for Personality Traits, Instrumentalists, and Vocalists.

Table 5

Means, Standard Deviation, Skewness, and Kurtosis for Personality Traits and Ensemble Section

Big Five Personality Traits

\begin{tabular}{lccccc}
\cline { 2 - 5 } Ensemble Section & Extro & Agree & Consc & Neuro & Open \\
\hline Strings $(N=25)$ & & & & & \\
Mean & 23.04 & 29.48 & 26.24 & 19.16 & 30.20 \\
Std. Deviation & 9.53 & 7.00 & 7.76 & 7.90 & 7.22 \\
Skewness & -.478 & -1.452 & -.179 & -.337 & -.217 \\
Kurtosis & -.315 & 1.60 & -.307 & -.099 & -.714 \\
Winds $(N=88)$ & & & & & \\
Mean & 24.20 & 30.89 & 26.54 & 19.94 & 31.94 \\
Std. Deviation & 8.270 & 5.68 & 6.43 & 8.13 & 5.49 \\
Skewness & -.420 & 1.856 & -.168 & -.674 & -.303 \\
Kurtosis & -.202 & -1.137 & -.432 & -.137 & -.489 \\
Percussion $(N=40)$ & & & & & \\
Mean & 21.87 & 29.93 & 25.21 & 19.56 & 30.58 \\
Std. Deviation & 8.95 & 5.51 & 6.26 & 7.98 & 5.46 \\
Skewness & -.723 & 1.688 & -.291 & -.703 & -.452 \\
Kurtosis & .223 & -1.176 & -.211 & -.023 & -.420
\end{tabular}


Table 5 Continued

Brass $(N=68)$

$\begin{array}{lccccc}\text { Mean } & 22.62 & 30.09 & 26.14 & 20.23 & 31.07 \\ \text { Std. Deviation } & 8.88 & 5.74 & 6.25 & 8.10 & 5.58 \\ \text { Skewness } & -.602 & 1.816 & -.359 & -.728 & .039 \\ \text { Kurtosis } & -.241 & -1.183 & -.320 & -.085 & -.551\end{array}$

Piano/Keyboard $(N=26)$

Mean

21.5

31.23

26.23

20.23

30.00

Std. Deviation

7.26

5.51

6.88

8.51

6.11

Skewness

$-.894$

$-1.292$

$-.036$

$-.561$

$-.767$

Kurtosis

$-.672$

1.220

$-.711$

$-.787$

.128

Soprano Voice $(N=57)$

Mean

23.51

31.47

26.12

17.26

30.89

Std. Deviation

7.92

5.00

7.10

8.16

6.28

Skewness

$-.077$

$-.639$

$-.662$

$-.010$

$-.446$

Kurtosis

$-.750$

.282

$-.588$

$-.667$

$-.579$

Alto Voice $(N=69)$

Mean

24.48

32.10

26.67

19.64

32.00

Std. Deviation

7.99

4.70

6.45

7.55

5.40

Skewness

$-.151$

$-.914$

$-.180$

$-.117$

$-.489$

Kurtosis

$-.264$

1.165

$-.698$

$-.689$

$-.085$

Tenor Voice $(N=26)$

Mean

22.77

31.73

27.77

21.65

32.96

Std. Deviation

9.21

5.40

4.61

7.62

4.25

Skewness

$-.155$

$-.495$

$-.414$

.144

.056

Kurtosis

$-.195$

$-.856$

.111

$-.855$

$-.784$

Bass Voice $(N=48)$

Mean

25.13

27.71

29.56

22.79

32.63

Std. Deviation

9.21

6.76

6.39

8.53

5.25

Skewness

$-3.56$

$-1.280$

.337

$-.572$

$-.411$

Kurtosis

$-.249$

1.175

$-1.199$

$-.297$

$-1.013$ 
Results of the MANOVA showed a significant main effect of Ensemble Section Choice, $\Lambda=.824, F(40,1803)=2.052, p=<.001$. The results across personality traits by instrument section showed significant differences in Agreeableness, $F(8,417)=3.55, p<.001, \eta^{2}=.064$, and Neuroticism, $F(8,417)=2.25, p=.023, \eta^{2}=.041$ (See Figures $6 \& 7$ ). The most significant difference was between the Alto Voice section $(N=48, M=32.10, S D=4.70)$ and the Bass Voice section $(N=69, M=27.71, S D=6.76)$. There was also a significant difference between Winds and Soprano Voice, Winds and Alto Voice, Percussion and Soprano Voice, and Percussion and Alto Voice (See Table 5). The largest differences were found in the Bass Voice section when compared to Piano/Keyboard, Soprano Voice, Alto Voice, and Tenor Voice. 


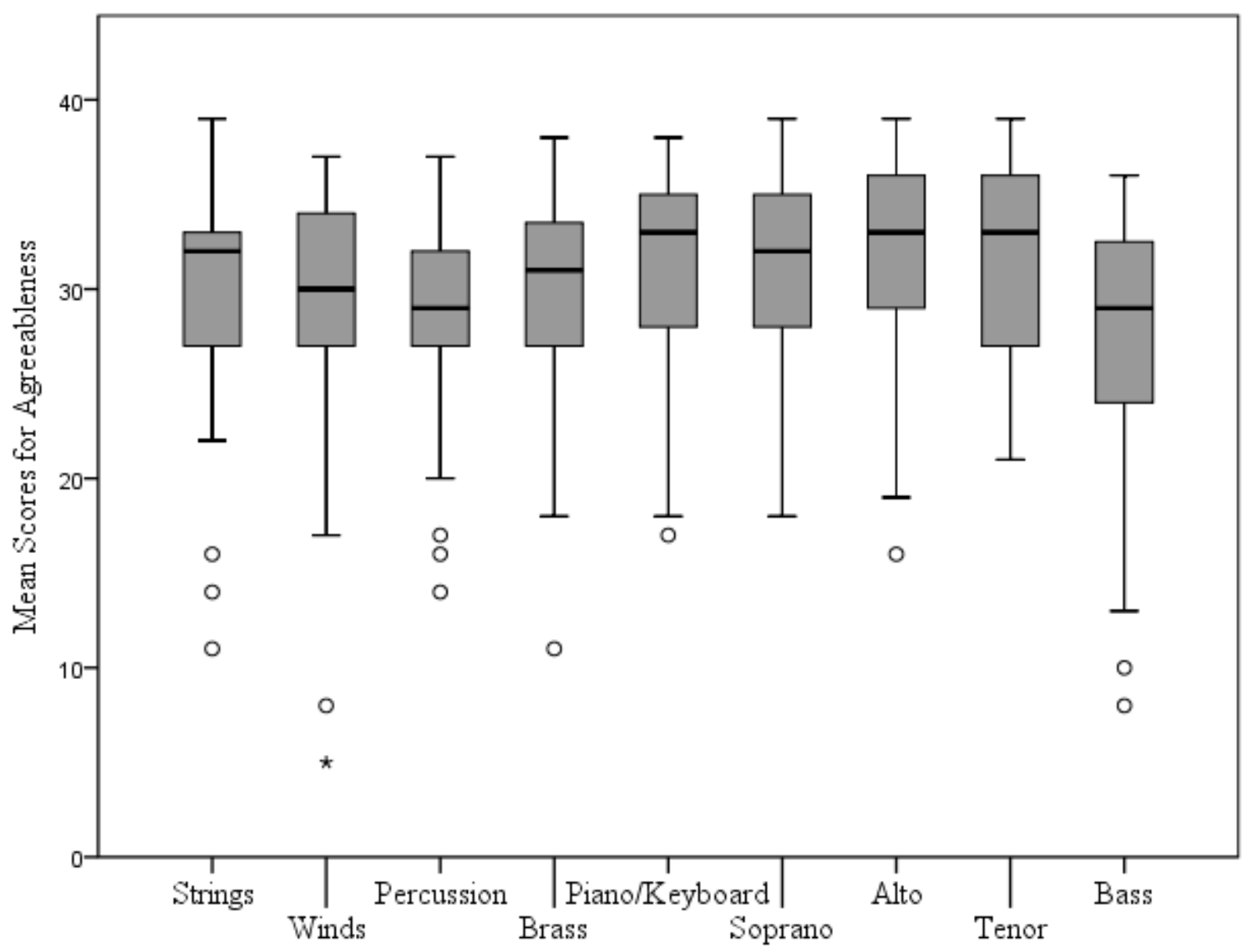

Figure 6

Graph for Agreeableness by Instrument Section

Table 6

Agreeableness Pairwise Comparison

\begin{tabular}{lcccc}
\hline Instrument Section & $N$ & $M$ & SEM & Sig. \\
\hline Winds $(N=88, M=29.24)$ & & & & \\
$\quad$ Soprano Voice & 57 & 31.47 & .969 & .002 \\
$\quad$ Alto Voice & 48 & 32.10 & .917 & .002 \\
$\quad \begin{array}{l}\text { Percussion }(N=40, M=28.65) \\
\quad \text { Soprano Voice }\end{array}$ & 57 & 31.47 & 1.176 & .017 \\
$\quad$ Alto Voice & 48 & 32.10 & 1.133 & .002 \\
Bass Voice $(N=69, M=27.71)$ & & & & \\
$\quad$ Piano/Keyboard) & 26 & 31.23 & 1.388 & .012 \\
$\quad$ Soprano Voice & 57 & 31.47 & 1.117 & .001 \\
$\quad$ Alto Voice & 48 & 32.10 & 1.071 & .000 \\
$\quad$ Tenor Voice & 26 & 31.73 & 1.388 & .004 \\
\hline
\end{tabular}


For Neuroticism, the largest difference was between the Bass Voice section scored and the Soprano Voice section (See Figure 6). The Soprano Voice section showed the largest difference between instrument sections: Winds, Brass, Tenor Voice, and Bass Voice.

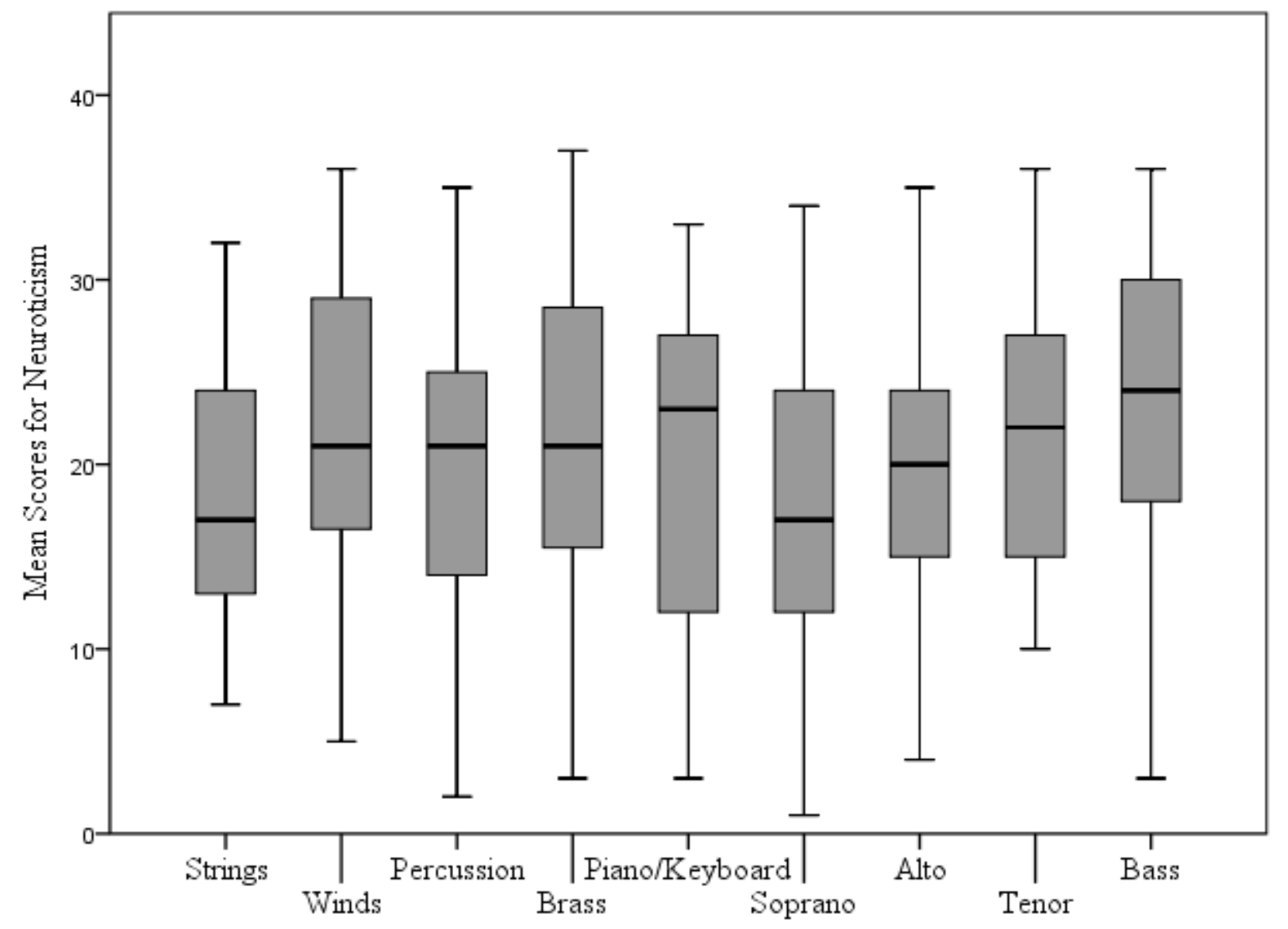

Figure 7

Graph for Neuroticism by Instrument Section 
Table 7

Neuroticism Pairwise Comparison

\begin{tabular}{lcccc}
\hline Instrument Section & $N$ & $M$ & SEM & Sig. \\
\hline $\begin{array}{l}\text { Soprano Voice }(N=57, M=17.26) \\
\text { Winds }\end{array}$ & 88 & 21.77 & 1.371 & .001 \\
Brass & 47 & 21.51 & 1.589 & .008 \\
Tenor Voice & 26 & 21.65 & 1.909 & .022 \\
$\quad$ Bass Voice & 69 & 22.79 & 1.580 & .001 \\
\hline
\end{tabular}

A post hoc pairwise comparison for Extroversion showed no statistically significant difference between ensemble sections, except for the Wind Section and Alto Vocalists ( $p=$ $.020)$, and Wind Section and Bass Vocalists $(p=.013)$. The Alto and Bass Vocalists were significantly more extroverted than the Wind Section. 


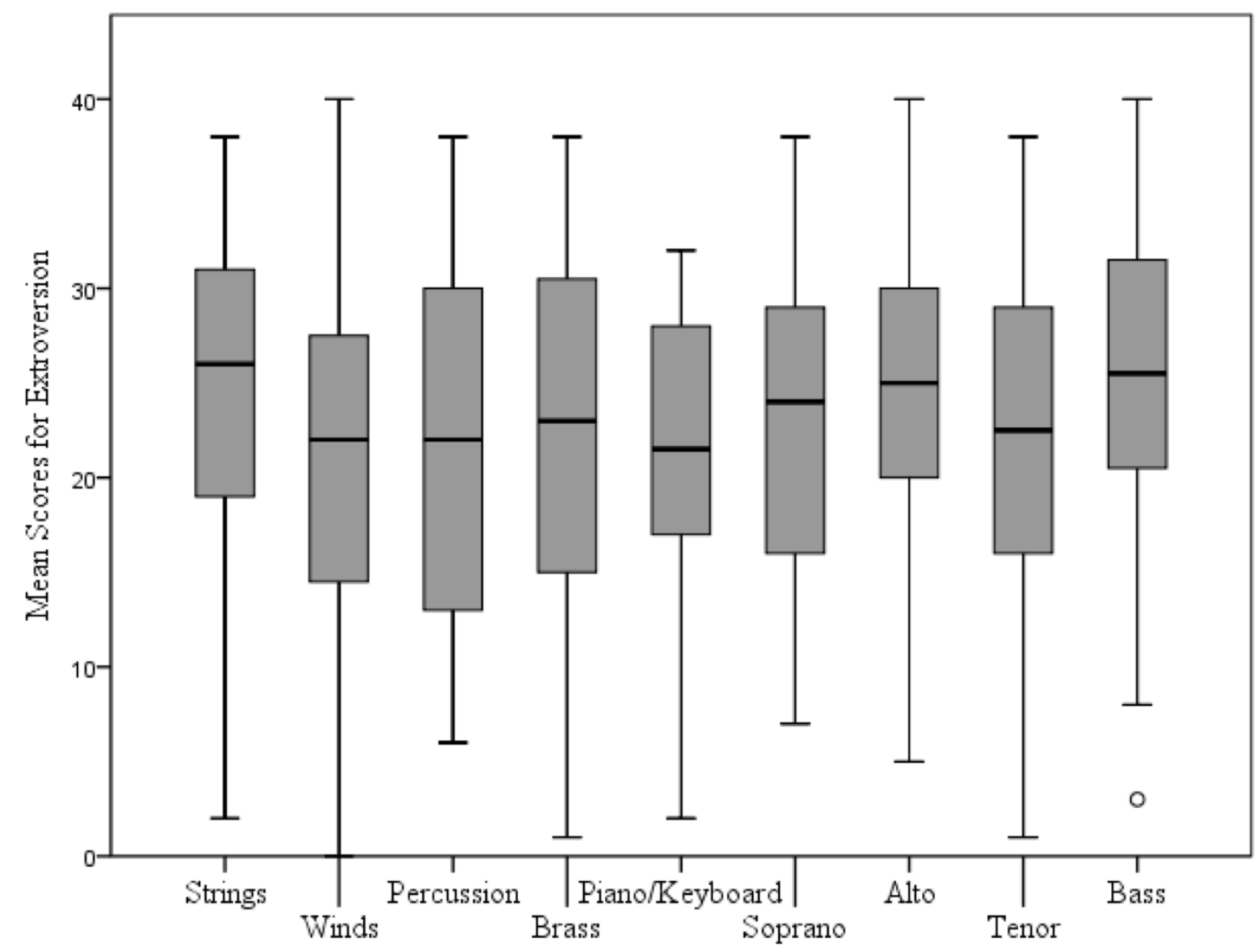

Figure 8

Graph for Extroversion by Instrument Section

Table 8

Extroversion Pairwise Comparison

\begin{tabular}{lcccc}
\hline Instrument Section & $N$ & $M$ & SEM & Sig. \\
\hline Winds $(N=88, M=21.17)$ & & & & \\
Alto & 69 & 24.48 & 1.418 & .020 \\
$\quad$ Bass & 48 & 25.13 & 1.583 & .013 \\
\hline
\end{tabular}


A post hoc pairwise comparison for Openness to Experience showed no statistically significant difference between ensemble sections, except for the Brass Section and Tenor Vocalists $(p=.021)$, and the Brass Section and Bass Vocalists $(p=.014)$. The Tenor and Bass Vocalists were significantly more open than the Wind Section.

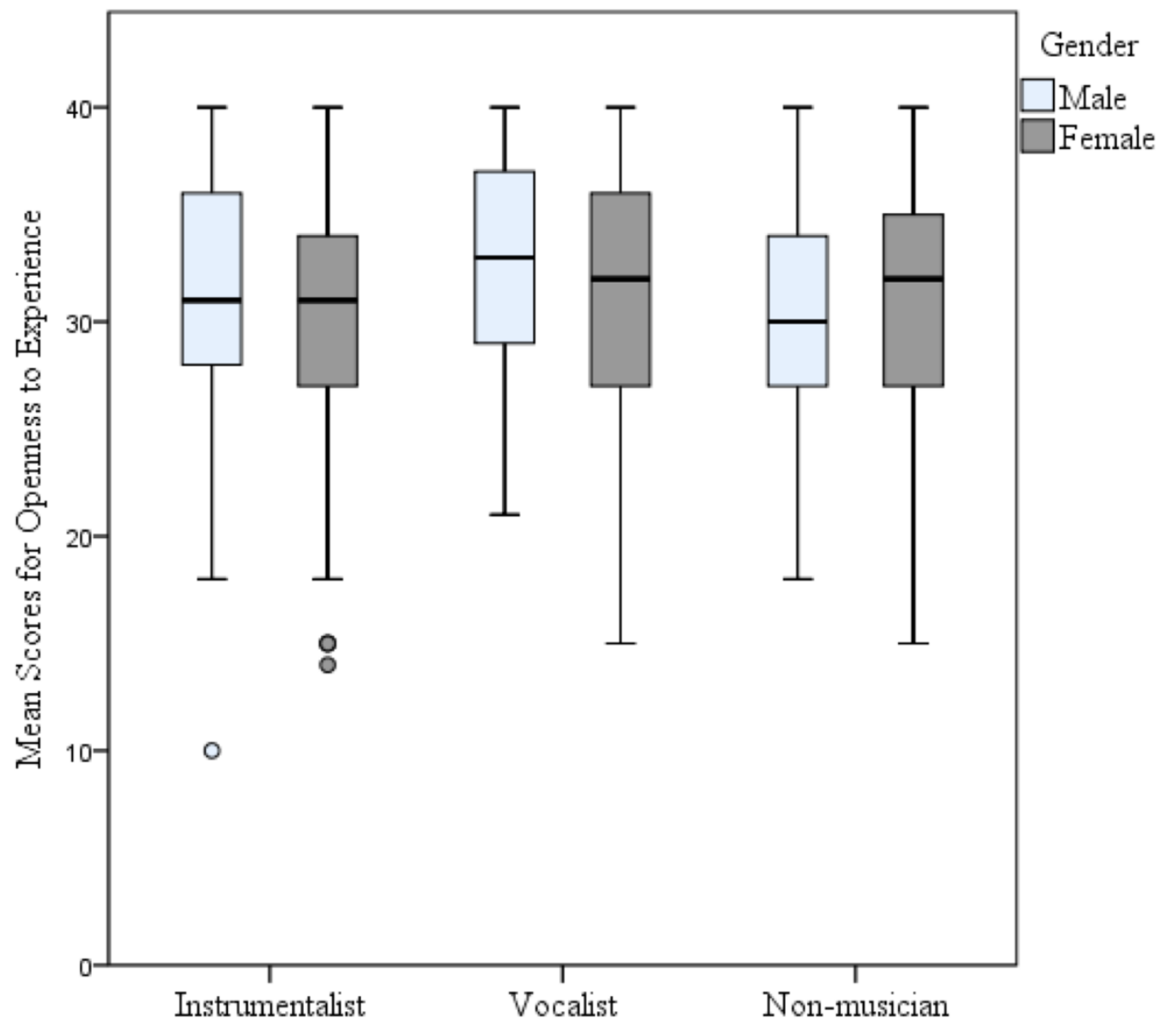

Figure 9

Graph for Openness to Experience by Instrument Section 
Table 9

Openness to Experience Pairwise Comparison

\begin{tabular}{lcccc}
\hline Instrument Section & $N$ & $M$ & SEM & Sig. \\
\hline Brass $(N=47, M=22.51)$ & & & & \\
$\quad$ Tenor & 26 & 22.77 & 1.368 & .020 \\
Bass & 48 & 25.13 & 1.149 & .013 \\
\hline
\end{tabular}

A post hoc pairwise comparison for Conscientiousness showed no statistically significant difference between ensemble sections.

\section{Summary of Results}

The results suggest that personality traits and gender are related to instrument section choice. Results show that vocalists are more extroverted than instrumentalists, specifically Altos and Basses. The most extroverted of the instrumental sections was the String section. By gender, male vocalists tended to be the most extroverted. Alto and Tenor Vocalists tended to score higher in Agreeableness, while the Bass Vocalists scored the lowest of all musicians. By gender, female vocalist scored the highest. Tenor Vocalists scored the highest in Conscientiousness and the Brass section scored the lowest. By gender, male musicians tended to score higher in Conscientiousness than females. For Neuroticism, the Basses scored the highest, while the Sopranos scored the lowest. Neuroticism is a reverse scored trait; the lower the score, the more emotionally stable the individual. By gender, male instrumentalists scored the highest in Neuroticism, while female vocalists scored the lowest. The Tenor Vocalists, Bass Vocalists, and Percussion sections scored the highest in Openness to Experience, while the Brass section scored 
the lowest. By gender, male vocalists scored the highest and female instrumentalists scored the lowest.

These data both confirm and conflict the findings of earlier studies. This could be due, in part, to the different personality inventories used in the comparison studies. While Buttsworth and Smith (1995) study utilizing Cattell's 16PF found musicians to be more sensitive and less intelligent, it is difficult to compare those findings with Goldberg's Big Five IPIP. However, it is possible to compare their findings for Emotional Stability (in which musicians scored high) as it corresponds to the Big Five's Neuroticism (in which the current study scores were high). While this may look like similar findings, Neuroticism is reverse scored; the higher score, the more emotionally unstable.

The current study also confirms Langendörfer's (2008) findings that string players tend to be more conscientious than brass and wind players, data from the current study also contrasts with Langedörfer which found no difference between ensemble sections in any of the other four personality traits. The current study also confirms the findings of Haller and Courvoisier (2010) which found musicians to have high mean scores in Extroversion and Agreeableness, and Kemp's (1981a) findings that vocalists are more extroverted than instrumentalists. MarchantHaycox and Wilson (1992) also had similar findings to the current study utilizing the Eysenck Personality Profiler (EPP). Their study found lower scores on emotional stability and higher scores on caution and introversion. However, as previously stated, not all personality inventories measure the same traits, making it difficult for direct comparison. 


\section{CHAPTER FIVE DISCUSSION}

This chapter reviews the results of the study in the context of the proposed research questions and offers potential explanations and future research directions pertaining to personality traits and music learning. Following a brief overview of the study purpose and procedures, the results are reviewed and contrasted with findings in current literature.

\section{Study Summary}

The purpose of this study was to examine the personality traits of collegiate and community ensemble musicians to examine relationships between instrument choice (vocal or instrumental) and personality traits, and ensemble choice and personality traits.

Participants for this study were 608 individuals, both musicians and non-musicians, from across the United States and ranged from $18-87$ years of age. Participants were administered the Big Five IPIP (Goldberg, 2009), via paper/pencil or online. The Big Five IPIP was chosen for its ease of distribution as well as the reliability of internal consistency between traits is 0.78 to 0.88 (Donnellan, Oswald, Baird, et al., 2006). Demographic questions (e.g., age, gender, race/ethnicity, instrumentalist or vocalist) were also included in the survey. The Big Five IPIP was utilized to measure personality. Each trait was measured by ten statements with a Likert scale of 1-5 (1 = "Strongly Disagree," 2 = "Somewhat Disagree," 3 = "Neutral," 4 = Somewhat Agree, and $5=$ "Strongly Agree").

The following descriptions provide an overview of traits included on the Big Five: Openness to Experience refers to artistic sensitivity, originality, and imagination. 
Conscientiousness refers to traits such as dependability, responsibility and organization. Extroversion traits are interpreted as excitement seeking, gregariousness, and warmth. Agreeableness refers to traits of likability, such as being good-natured, forgiving and trustworthy. Neuroticism measures levels of anxiety, self-consciousness and depression (Viswesvaran \& Ones, 2000).

The final participant pool consisted of Collegiate, Community, Other ensemble and Nonmusicians. To ensure group independence, participants who were engaged in more than one ensemble were asked to report the primary or favorite ensemble in which they were currently participating. This could be considered a strength for the community sample; however, the opportunity for the collegiate sample to be engaged in multiple ensembles could be considered a limitation in terms of understanding personalities inherent to engaging in one particular ensemble. Likewise, individuals who play more than one instrument were asked to report their primary instrument.

While the study population consisted primarily of white females, there was diversity in the number of ethnicities reported. Most surprising was the large number of Middle Eastern participants, which could be due to the inclusion of the university sample. Also of interest was the number of Scottish Pipe Band participants.

Gender, Personality Traits, and Instrument Choice (Vocalists and Instrumentalists)

To what extent do personality traits (Agreeableness, Conscientiousness, Extroversion, Neuroticism, and Openness to Experience) relate to ensemble choice (instrumental versus vocal) and gender? 
A significant difference was found between Vocalists and Instrumentalists for personality trait Extroversion. Vocalists were significantly more likely to be extroverted than instrumentalists. These results support the earlier findings of Cameron, Duffy, \& Wainwright, (2014), Kemp (1981b), Lanning (1990), and Reardon (2009). Male vocalists were the most extroverted of the participating musicians, and female instrumentalists the most introverted. Individuals who score higher in Extroversion enjoy being with others and seek fulfillment in their company (Myers, 1998). Extroverted people are more likely to be kinesthetic learners and engage in diverse activities. In contrast, individuals who score low in Extroversion tend to get their energy from within and prefer to work alone (John \& Naumann, 2007). While Extroverts seek social stimulation, Introverts seek to lower social stimulation (TED, 2016). They are private individuals who tend to learn best through reflection (Myers, 1998).

Vocalists were also found to be higher in Agreeableness than Instrumentalists. Individuals who score high in Agreeableness tend to be polite, avoid conflict and work well in group settings. These would be very helpful traits for an individual in any ensemble, but particularly in vocal ensembles with high Extroversion. The Agreeableness trait works as an editor; individuals with high scores think before speaking, thus helping avoid or able to resolve conflict.

There was no significant group interaction for Conscientiousness between Vocalists and Instrumentalists. Individuals who score high in Conscientiousness are hard workers and follow the rules. They are persistent, honest, organized, and plan ahead; all traits that would lead to successful musicianship. In order to achieve proficiency, hours are spent in individual practice. Those with higher Conscientiousness scores tend to be self-motivated and achievement driven, which can lead to more productive practice sessions. 
Neuroticism refers to emotional stability. Results for this study showed that Instrumentalists tended to score higher than Vocalists in Neuroticism. Since this is a reverse scored trait, lower scores indicate more emotional stability. Male musicians scored higher than female musicians in both Neuroticism and Conscientiousness. Future research could examine the relationship, as the aim for perfection due to high Conscientiousness could contribute to scoring higher in Neuroticism.

Like Conscientiousness, Openness to Experience was found to be a common trait among musicians. The male instrumentalists scored the highest in this trait, while the female instrumentalists scored the lowest. This could be due to the need for creativity or to solve musical problems and challenges. However, the non-musician sample scored similarly to the musicians. Their high scores in Openness to Experience trait may be attributed to their willingness to try or learn new things (John, et al., 2008) and volunteering for this study.

Personality and Ensemble Section

To what extent do personality traits (Agreeableness, Conscientiousness, Extroversion, Neuroticism, and Openness to Experience), relate to ensemble section?

For personality trait Extroversion, the Bass and Alto Voice sections scored the highest. Of the Instrumentalists, the Strings section and Brass section were the most extroverted, which conflicted with previous studies finding Percussionists and Brass being the most extroverted instrumentalists (Martin, 1976; Torrance \& Bugos, 2016). Higher Extroversion scores in vocalists were not surprising as vocalists project their own personality through voice as compared to that of an instrument (Kemp, 1981a). 
One explanation for extroversion in the String section could be location. The violin section of the orchestra sits right in front of and has direct eye-contact with the conductor and other members of their section, which is important to Extroverts (TED, 2016). Brass players, on the other hand, are located near the back of the orchestra and do not play as much as the strings, leaving time for communication with section members and awaiting their next cue (Langendörfer, 2007). Brass players also have the added stress of loud, sudden entrances which require self-assurance.

Individuals scoring high in Agreeableness are cooperative and compassionate people who enjoy helping others and avoid conflict when possible. Data from this study showed that vocalists scored higher in Agreeableness than instrumentalists. The section scoring highest in Agreeableness was the Alto Vocalist section followed by the Tenor and Soprano Vocalists section. Piano/keyboard players scored the highest of all instrumentalists, while the Bass Voice section scored the lowest of all musicians.

Conscientiousness has been found to be a strong trait amongst musicians (Cameron, Duffy\& Wainwright, 2015; Kemp, 1981a; Reardon, 2009; Torrance \& Bugos, 2016; Wubbnehorst, 1999). The Tenor Voice section scored the highest of all musicians. The Alto and Bass Voice sections also scored high in Conscientiousness. This could be due to the fact that the middle an while the section scoring lowest was the Brass. Low scores in Conscientiousness should not always be viewed as a negative, especially for jazz musicians. Lower scores are associated with spontaneity and flexibility, which are important skills for jazz musicians whose repertoire requires a great deal of improvisation.

Neuroticism measures emotional stability. The highest scores in Neuroticism were found in the Bass Voice and Wind sections. Again, it is interesting to find high scores in the same 
sections for both Conscientiousness and Neuroticism. The section scoring the lowest in Neuroticism was the Soprano section. In general, Neuroticism measures not only emotional stability but one's level of positive psychological health. Individuals who score high in this trait may have problems dealing with anxiety, depression, and insecurity (Costa \& McCrae, 1992).

Finally, Openness to Experience refers to an individual's mental and experiential life, as well as describing cognitive style. It also measures individual differences in imagination and creativity; i.e., what differentiates artistic and creative people from more pragmatic, conventional individuals (John, Naumann, \& Soto, 2008). The highest scoring ensemble section was the Tenor Voice section followed by the Bass Voice section. The highest scoring instrumental section was the Percussion section. This is not surprising as the percussionists are required to play many instruments within their own section as compared to the strings, which play only one throughout a concert. The lowest scores for Openness to Experience were found in the Brass and Piano/Keyboard sections.

\section{Limitations}

The results of this study are not meant to suggest that personality is the deciding factor for instrument and/or ensemble choice. This is intended as a guideline, not a means, to select or discourage students based upon personality traits. Other factors such as embouchure and physical ability should be taken into account as well.

A prominent limitation is the uneven distribution of instruments throughout the instrumental sections participating in this study. A wider range of instrumentalists, evenly distributed, would have been more conducive to examining comparisons by instrument choice. 
Another limitation is the number of male participants. Although the survey was distributed to an equal number of males and females, almost twice as many females chose to respond as males. Further studies that include a more gender-equal distribution will capture information on associations between personality traits of male participants and musicianship.

Finally, the self-report survey itself had limitations. Due to the length, participants may have fatigued and not finished or rushed to complete it without careful consideration of their responses. When examining the timelines of the incomplete online surveys, some were only open long enough to read the Waiver of Consent. Others completed the demographic survey and part of the Big Five then chose to refrain from participation. However, when looking at the analytics, the average completion time was approximately seven minutes.

\section{Recommendations}

While some findings were consistent with previous studies (e.g., vocalists are more extroverted than instrumentalists) (Kemp, 1981c; Lanning, 1990; Reardon, 2009; Wubbenhorst, 1999), others were not. For instance, the higher scores for Strings were in conflict with the findings of Kemp (1981a), and Bell \& Cresswell (1984). Therefore, the predominant personality traits within instrumental and vocal sections maybe changing when compared to studies from the last century.

Future longitudinal research could investigate the personalities of musicians and musical engagement beginning in high school, with three follow-up sessions (at 20 years of age, early 30s and early 40s). This would provide a clearer, overall picture of the musicians' personality from young adulthood to middle age. Many traumatic events occur during this period (e.g., marriage, children, military service or conflict, divorce), which could influence personality trait 
outcomes (Gibson \& Hodgetts, 2013). These events may also influence an individual's level of music engagement.

Researchers could also benefit from learning about the personality traits of individuals engaged in smaller, non-traditional student created or lead ensembles (e.g., rock bands, fivevoice a capella ensemble). These small ensembles are now being included in the curriculum in some high schools as well as being formed separately from the school. Collecting data by recruiting students not enrolled in the larger traditional ensembles will track newer ways of creating music as technology advances.

Another benefit of a longitudinal study is that data would be more consistent by utilizing the same personality inventory to measure personality traits instead of trying to compare results from different inventories (e.g., MBTI, Big Five IPIP, 16 PF). There are manuals to assist in aligning correlations between the different personality inventories; however, there is no direct correlation to any of the MBTI dichotomies for Neuroticism or Emotional Stability (Furnham, 1996).

\section{Implications for Music Education}

Student musicians come from many different backgrounds (e.g., socio-economic status, life events, musical experience) which influence their personality (Roberts, Wood, \& Caspi, 2008) and these differences may influence learning styles and outcomes (Corrigall, Schellenberg, \& Misura, 2013). Further investigation into these factors could lead to a better understanding of how personality influences musical ensemble engagement as well as assist the ensemble director with repertoire choice, lesson planning, and teaching style. 
Research suggests a relationship between learning styles and personality traits (Corrigall, Schellenberg, \& Misura, 2013). Certain personality traits have also been positively linked to academic success, specifically Openness to Experience and Conscientiousness (TED, 2016). Neuroticism, however, has been negatively linked (Chamarro-Premuzic \& Furnham, 2007). Individuals scoring high in this trait tend to withdraw when faced with academic difficulties. Furnham's (1992) study suggests that different personalities use different decision making strategies and have different cognitive styles. Some researchers have found how students take in information and react to their environment is influenced by personality (Lawrence, 1982). For instance, educators whose MBTI type is Introverted (I), Sensing (S), and Judging (J) tend to have relatively quiet, orderly classrooms in comparison to educators whose MBTI type is Extroverted (E), Intuitive $(\mathrm{N})$, and Perceiving $(\mathrm{P})$, who's classroom may seem chaotic and noisy. The communication style of extroverts and introverts differs greatly. Extroverts tend to prefer to be in close proximity with whom they are conversing, make lots of eye contact, and speak in direct, black and white terms. Introverts, however, prefer a bit of distance between themselves and the person with whom they are conversing, and tend to speak contextually (TED, 2016). Depending on the personality and learning style of the student, either classroom could be a wonderful learning experience or an exercise in futility.

However, learning styles, as it pertains to teaching, remains controversial. Roher and Pashler (2012) argue that, after a lengthy review of literature, little data to support style-based instruction was found. While there have been a few studies with positive findings, their effect sizes are unknown. Conversely, there have been a large number of unsuccessful studies published with null findings. While Roher and Pashler agree that individual learning styles exist, 
the authors question whether student-tailored or style-based learning is cost-effective or efficacious compared to other less expensive interventions.

Despite these findings, there are many practical implications for the classroom. For instance, individuals who score high in Agreeableness are the people pleasers and seek to establish warm relationships with others. Teachers can promote this by creating a positive atmosphere, although this can be a difficult task due to the competitive nature found in some ensembles (e.g., first violin of an orchestra, bass section leader in a chorus). However, by creating a nurturing environment, students will feel more comfortable, which can to lead to more productive rehearsals.

Students who score high in Conscientiousness are the diligent, persistent musicians who strive for perfection. These students prefer structure. A well-framed rehearsal with planned moments of down-time will keep students focused. In a chorus which is predominantly extroverted, turn and talk about a specific topic for 60 seconds would be a good choice for a mini-break. For more introverted instrumentalists, a few minutes for written reflection in a music journal would be preferable. Rubrics and a visual schedule are also much appreciated by this group as they prefer to be organized and make assignment deadlines.

Another common trait among musicians is Openness to Experience. Individuals scoring high in Openness are often described as artistic, poetic, fantasy-prone, and perceptive (DeYoung, Quilty, Peterson, \& Gray, 2013). They are also more likely to pursue, find, and assimilate answers to questions than those scoring low in Openness to Experience. One strategy to try would be a student lead rehearsal with the director becoming a facilitator and partner in the learning process (Elias \& Merriam, 1984). The job of the facilitator is to ensure that students have the support they need to do their best thinking. The director may lecture for a short period 
of time, outlining the objectives for the rehearsal, but student centered learning allows the students to work through the lesson to complete the planned activity. This strategy may be successful as it plays into the strengths of individuals who score high in Openness to Experience, engaging critical thinking skills.

\section{Conclusion}

In conclusion, this study found significant differences between the personalities of the ensembles studied, as well as their instrument or voice section. While vocalists are generally more extroverted than instrumentalists overall, there are instrumental ensembles as a whole that tend to attract more extroverted personalities (e.g., jazz band) than some vocal ensembles (e.g., women's choir). There are also personality traits that are commonly shared between instrumentalists and vocalists. Conscientiousness and Agreeableness seem to be important traits

for musicians overall. These goal-driven individuals strive to attain the high musicianship skills needed to perform while working in a group situation, which calls for high levels of Agreeableness. Neuroticism also seems to be common among musicians. According to Dyce \& O'Connor (1994), this could be a necessary trait for music performance, as musicians draw from personal experience to evoke emotion and may even be used as a therapeutic tool to purge negative emotions.

Creative activities, such as making music, may also ward against anxiety (Storr, 1972). Openness to Experience is the willingness to try new things. Instrumentalists have been thought of as being somewhat more open than Vocalists as they generally play more than one instrument. However, current research shows that Vocalists are scoring higher in Openness to Experience 
than in earlier studies, which may mean one of two things: 1) vocalists are singing multiple genres, or 2) vocalists are singing with more than one ensemble or branching out solo.

After examining the personalities of musicians from across the United States, from all walks of life, and different stages of life, Brian Little's quote became quite prophetic: Individuals “... are like all other people, like some other people, and like no other person." It is the hope of this researcher that this study will add to the research of the relationship between personality and a range of musically related experience. 


\section{References}

Allport, G.W. (1921). Personality and character. Psychological Bulletin, 18, 441-455.

Allport, G.W., \& Odbert, H.S. (1936). Trait names: A psycho-lexical study. Psychological Monographs, 47(1), 1-171.

Armstrong, S. J., Peterson, E. R., \& Rayner, S. G. (2011). Understanding and defining cognitive style and learning style: A Delphi study in the context of educational psychology. Educational Studies, 38:4, 449-455, doi:10.1080/03055698.2011.643110

Barenboim, N., \& Winter, D. (2008). History of modern personality and research. In O. P. John, R. W. Robins \& L. A. Pervin (Eds.), Handbook of personality: Theory and research (3rd ed.) New York: Guilford Press.

Bell, C. R., \& Cresswell, A. (1984). Personality differences among musical instrumentalists. Psychology of Music, 12, 83-93. doi:10.1177/0305735684122002

Benedek, M., Borovnjak, B., Neubauer, A. C., \& Kruse-Weber, S. (2014). Creativity and personality in classical, jazz and folk musicians. Personality and Individual Differences, 63, 117-121. doi:10.1016/j.paid.2014.01.064

Briggs-Myers, I. (www.myersbriggs.org).

Bonneville-Roussy, A., \& Rentfrow, P. J., Xu, M. K., \& Potter, J. (2013). Music through the ages: Trends in musical engagement and preferences from adolescence through middle adulthood. Journal of Personality and Social Psychology, 105(4), 703-717. doi: $10.1037 / \mathrm{a} 0033770$

Borgatta, E. F. (1964). The structure of personality characteristics. Behavioral Science, 9, 8-17.

Bowers, J. M. \& Tick, J. (1986). Women making music: The Western art tradition, 1150-1950. Urbana: University of Illinois Press.

Brown, K. D. (2016). Adult community orchestras in Texas: Activity and background profiles of participants with a report of organizational standing (Order No. 10016855). Available from ProQuest Dissertations \& Theses Global. (1767414899).

Builione, R., \& Lipton, J. (1983). Stereotypes and personality of classical musicians. Psychomusicology: A Journal of Research in Music Cognition, 3, 36. doi: $10.1037 / \mathrm{h} 0094257$ 
Busato, V. V., Prins, F. J., Elshout, J. J., Hamaker, C. (1999). The relation between learning styles, the Big Five personality traits and achievement motivation in higher education. Personality and Individual Differences, 26(1) 129-140. http://doi.org/10.1016/S01918869(98)00112-3

Buss, D. M. (1984). Evolutionary biology and personality psychology: Toward a conception of human nature and individual differences. American Psychologist, 39(10), 1135-1147. doi:10.1037/0003-066X.39.10.1135

Butkovic, A., \& Dopudj, D. R. (2017). Personality traits and alcohol consumption of classical and heavy metal musicans. Psychology of Music, 45(2), 246 - 256.

doi: $10.1177 / 0305735616659128$

Butkovic, A., Ullén, F., \& Mosing, M. A. (2015). Personality related traits as predictors of music practice: Underlying environmental and genetic influences. Personality and Individual Differences, 74, 133-138. doi:10.1016/j.paid.2014.10.006

Buttsworth, L. M., \& Smith, G. A. (1995). Personality of Australian performing musicians by gender and by instrument. Personality and Individual Differences, 18(5), 595-603. doi:10.1016/0191-8869(94)00201-3

Cameron, J. E., Duffy, M., Glenwright, B. (2014). Singers take stage! Personality traits and stereotypes of popular musicians. Psychology of Music, doi:10.1177/0305735614543217

Cattell, H. E. P., \& Meade, A.D. (2008) The sixteen personality factor questionnaire (16PF). In Boyle, G. J., Matthews, G., \& Saklofske, D. H. (Eds.), The SAGE Handbook of Personality Theory and Assessment. Los Angeles, CA: SAGE Publications.

Cattell, R. B. (1943). The description of personality: Basic traits resolved into clusters. Journal of Abnormal and Social Psychology, 38, 476-506.

Cattell, R. B. (1945a). The description of personality: Principles and findings in a factor analysis. American Journal of Psychology, 58, 69-90.

Cattell, R. B. (1945b). The principle trait clusters for describing personality. Psychological Bulletin, 42, 129-161.

Cattell, R. B. (1973). Personality and Mood Questionnaire. Oxford, England: Jossey-Bass.

Cattell, R. B., Eber, H. W., Tatsuoko, M. M. (1970). Handbook for the Sixteen Personality Factor Questionnaire (16PF). Champaign, IL: IPAT.

Chang, B. (2007). Band instrument selection by middle and high school students in international schools: Personality predictors and various influences (Doctoral dissertation). Available from ProQuest Dissertations \& Theses database. (304805690)

Chamorro-Premuzic, T., \& Furnham, A. (2003). Personality traits and academic performance. European Journal of Personality, 17, 237-250. 
Chamorro-Premuzic, T., \& Furnham, A. (2008). Personality, intelligence and approaches to learning as predictors of academic performance. Personality and Individual Differences, 44(7), 1596-1603. http://doi.org/10.1016/j.paid.2008.01.003

Chamorro-Premuzic, T., Furnham, A., \& Lewis, M. (2008). Personality and approaches to learning predict preference for different teaching methods. Learning and Individual Differences, 17(3), 241-250. http://doi.org/10.1016/j.lindif.2006.12.001

Clark, M. H., \& Schroth, C. A. (2010). Examining relationships between motivation and personality among college students. Learning and Individual Differences, 20, 19-24. doi:10.1016/0j.lindif.2009.10.002

Conrad, M. A. (2006). Aptitude is not enough: How personality and behavior predict academic performance. Journal of Research in Personality. 40, 339-346.

Conway, C. (2000). Gender and musical instrument choice: A phenomenological investigation. Bulletin of the Council for Research in Music Education, 146, 1-17.

Cornelius, S. and Natvig, M. (2012). Music and Gender. Music: A Social Experience. Pearson Education, Inc.: Boston, MA.

Corrigall, K. A., Schellenberg, E. G., \& Misura, N. M. (2013). Music training, cognition, and personality. Frontiers in Psychology, 4, 222. doi:10.3389/fpsyg.2013.00222

Costa, P. T., \& McCrae, R. R. (1992). Professional Manual: Revised NEO Personality Inventory (NEO-PI-R) and NEO Five-Factor Inventory (NEO-FFI). Odessa, FL: Psychological Assessment Resources.

Costa, P. T., \& McCrae, R. R. (1995). Domains and facets: Hierarchical personality assessment using the Revised NEO Personality Inventory. Journal of Personality Assessment, 64(1), 21-50. http://dx.doi.org.ezproxy.lib.usf.edu/10.1207/s15327752jpa6401_2.

Csikszentmihalyi, M. (1996). The creative personality. Psychology Today, 29(4), 36-40.

Csikszentmihalyi, M., \& Getzels, J. (1973). The personality of young artists: An empirical and theoretical exploration. British Journal of Psychology, 64, 91-104. doi:10.1111/j.20448295.1973.tb01331.x

Cutietta, R., \& McAllister, P. (1997). Student personality and instrumental participation, continuation and choice. Journal of Research in Music Education, 45, 282-294. doi: $10.2307 / 3345587$

Davies, J. B. (1978) The Psychology of Music. Stanford University Press: Stanford, CA.

De Raad, B. (2000). The Big Five Personality Factors: The psycholexical approach to personality. Hogrefe \& Huber Publishers: Ashland, OH. 
Dews, C. L. \& Williams, M. S. (1989). Student musicians' personality stules, stresses, and coping patterns. Psychology of Music, 17, 37-47. doi:10.1177/0204635689171004.

Digman, J. M. \& Takemoto-Chock, N. K. (1981). Factors in the natural language of personality: Re-analysis and comparison of six major studies. Multivariate Behavioral Research, 16, 149-170.

Donnellan, M. B., Oswald, F. L., Baird, B. M., \& Lucas, R. E. (2006) The mini-IPIP scales: Tiny-yet-effective measures of the Big Five Factors of personality. Psychological Assessment, 18(2), 192 - 203. doi: 10.1037/1040-3590.18.2.192

DuBois, P. L. (1970). A history of psychological testing. Boston: Allyn \& Bacon.

Duff, A., Boyle, E., Dunleavy, K., \& Ferguson, J. (2004). The relationship between personality, approach to learning and academic performance. Personality and Individual Differences, 36(8), 1907-1920. http://doi.org/10.1016/j.paid.2003.08.020

Dunn, P. G., DeRuyter, B. ${ }^{\text {b }}$, \& Bouwhuis, D. G. (2012). Toward a better understanding of the relation between music preference, listening behavior, and personality. Psychology of Music, 4, 411-428.

Elias, J. and Merriam, S. (1984). Philosophical foundations of adult education. (Rev. ed.). Malabar, FL: Robert E. Krieger.

Eysenck, H. J. \& Eysenck, S. B. G. (1975). The Eysenck Personality Questionnaire. London: Hodder and Stoughton.

Farsides, T. \& Woodfield, R. (223). Individual differences and undergraduate academic success: The roles of personality, intelligence, and application. Personality and Individual Differences, 34, 1225-1243.

Furnham, A. (1996). The big five versus the big four: The relationship between the MyersBriggs Type Indicator (MBTI) and NEO-PI five factor model of personality. Personality and Individual Differences, 26(2), 303-307. doi:10.1016/1091-8869(96)00033-5.

Gibbons, C. F. (1990). The personality of the performing musician as measured by the MyersBriggs Type Indicator and the reported presence of musical performance anxiety (Doctoral dissertation). Available from ProQuest Dissertations \& Theses database. (303794320)

Gibson, J. \& Hodgetts, R. (2013). Readings and Exercises in Organizational Behavior. Saint Louis: Elsevier Science.

Goldberg, L. R. (1981). Language and individual differences: The search for universals in personality lexicons. In L. Wheeler (Ed.), Review of personality and social psychology (Vol. 2, pp. 141-165). Beverly Hills: Sage. 
Goldberg, L. R. (1990). An alternative "Description of Personality": The Big-Five Factor structure. Journal of Personality and Social Psychology, 59(6), 1216-1229.

Greenberg D. M., Baron-Cohen S., Stillwell, D.J., Kosinski, M., Rentfrow, P.J. (2015). Musical preferences are linked to cognitive styles. PLoS ONE 10(7): e0131151. doi:10.1371/journal.pone.0131151

Guernole, N., \& Chernyshenko, O. (2005). The suitability of Goldberg's Big Five IPIP personality markers in New Zealand: A dimensionality, bias, and criterion validity evaluation. New Zealand Journal of Psychology, 32(2), 86 - 96.

Haller, C. S. \& Coursoivsier, D. S. (2010). Personality and thinking style in different creative domains. Psychology of Aesthetics, Creativity, and the Arts, 4, $149-160$.

Hazrati-Viari, A., Rad, A. T., \& Torabi, S. S. (2011). The effect of personality traits on academic performance: The mediating role of academic motivation. Procedia-Social and Behavioral Sciences, 32, 367-371. doi:10.1016/j.sbspro.2012.01.055

Hallam, S., Rogers, L., \& Creech, A. (2008). Gender differences in musical instrument choice. International Journal of Music Education, 26, 7-19. doi:10.1177/0255761407085646.

Hogan, R. (1983). A socioanalytic theory of personality. In M. M. Page (Ed.) Nebraska Symposium on Motivation (pp. 55-89). Lincoln: University of Nebraska Press.

Honey, P. \& Mumford, A. (1992). The manual of learning styles. Maidenhead: Peter Honey.

Hudson, M. L., II. (2004). Relationships among personality types, timbre preferences, and choice of instrument by beginning band students in selected schools in southern Mississippi (Doctoral dissertation). Available from ProQuest Dissertations \& Theses database. (305125836)

Hyden, J. M., Jr. (1979). Musical style and instrument preferences as correlates of personality variables (Doctoral dissertation). Available from ProQuest Dissertations \& Theses database. (302999598)

Jackson, C. \& Lawty-Jones, M. (1996). Explaining the overlap between personality and learning style. Personality and Individual Differences, 20(3), 293-300. https://doi.org/10.1016/0191-8869(95)00174-3

John, O., \& Naumann, L. (2007). Correlations of BFI sales and self-reported act frequencies in an undergraduate sample. Unpublished data, Institute of Personality and Social Research, University of California at Berkeley.

John, O., Naumann, L., \& Soto, C. (2008). Paradigm shift to the integrative big five trait taxonomy: History, measurement, and conceptual issues. In O. P. John, R. W. Robins \& L. A. Pervin (Eds.), Handbook of personality: Theory and research (3rd ed.) New York, NY: Guilford Press. 
John, O. P. \& Srivastava, S. (1999). The Big Five trait taxonomy: History, measurement, and conceptual issues. In L. A. Pervin \& O. P. John (Eds.) Handbook of personality: Theory and research (2nd ed.) (pp. 102-138). New York, NY: Guilford Press.

Kaufman, J. C., Pumaccahu, T. T., and Holt, R. E. (2013) Personality and creativity in realistic, investigative, artistic, social, and enterprising college majors. Personality and Individual Differences, 54, 913-917.

Kemp, A. E. (1979). The personality structure of composers and performing musicians. Doctoral dissertation, University of Sussex (British Library Serial No. D29503/80)

Kemp, A. E. (1981a). Personality differences between the players of string, woodwind, brass and keyboard instruments, and singers. Bulletin of the Council for Research in Music

Education, 66/67 ISME. Report of the Eighth International Seminar of Research in Music Education, 33-38. Retrieved from http://www.jstor.org/stable/40317663

Kemp, A. E. (1981b). The personality structure of the musician: I. Identifying a profile of traits for the performer. Psychology of Music, 9, 3-14. doi:10.1177/03057356810090010201.

Kemp, A. E. (1981c). The personality structure of the musician: II. Identifying a profile of traits for the composer. Psychology of Music, 9, 69-75. doi10.1177/030573568192007

Kemp, A. E. (1982a) Personality traits of successful music teachers. Proceedings of the Ninth International Research Seminar. Psychology of Music, Special Issue, 72-75. ISSN:17413087.

Kemp, A. E. (1982b). The personality structure of the musician: III. The significance of sex differences. Psychology of Music, 10, 48-58. doi:10.1177/0305735682101006.

Kemp, A. E. (1982c). The personality structure of the musician: IV. Incorporating group profiles into a comprehensive model. Psychology of Music. 10, 3-6. doi:10.1177/0305735682102001.

Kemp, A. E. (1996). The musical temperament: Psychology and personality of musicians. Oxford, England: Oxford University Press. doi:10.1093/acprof:oso/9780198523628.001.0001.

Kolb, D. (1984). Experiential learning. Englewood Cliffs, NJ: Prentice-Hall.

Komarraju, M., Karau, S. J., Schmeck, R. R., \& Avdic, A. (2011). The big five personality traits, learning styles, and academic achievement. Personality and Individual Differences, 51(4), 472-477. doi:10.1016/j.paid.2011.04.019.

Lawrence, G. (1982). People types and tiger stripes: A practical guide to learning styles. Gainesville, FL: Center for Applications of Psychological Type. 
Langendörfer, F. (2008). Personality differences among orchestra instrumental groups: Just a stereotype? Personality and Individual Differences, 44(3), 610-620.

doi:10.1016/j.paid.20007.09.027.

Langmeyer, A., \& Guglhör-Rudan, A., \& Tarnai, C. (2015). What do music preferences reveal about personality? Journal of Individual Differences, 3, 234-247. doi:10.1027/16140001/a000082.

Lanning, A. M. (1990). Personality characteristics of undergraduate music majors in selected Oklahoma universities: An investigation of relationships as measured by the MyersBriggs Type Indicator (Doctoral dissertation). Available from ProQuest Dissertations \& Theses database. (303879102)

Li, W., Li, X., Huang, L., Kong, X., Yang, W., Wei. D., Li, J., Cheng, H., Zhang, Q., Qui, J., and Liu, J. (2014). Brain structure links trait creativity to openness to experience. Social Cognitive and Affective Neuroscience Advance Access, 10(2), 191-198. doi:10.1093/scan/nsu041

Little, B. (2016, July). Who are you really? The puzzle of personality. [Video file]. Retrieved from https://www.ted.com/talks/brian_little_who_are_you_really_the_puzzle_of_ personality

MacLellan, C. R. (2011). Differences in Myers-Briggs personality types among high school band, orchestra, and choir members. Journal of Research in Music Education, 59(1), 85100. doi:10.1177/0022429410395579.

Marchant-Haycox, S. E. and Wilson, G. D. (1992). Personality and stress in performing artists. Personality and Individual Differences, 13(10), 1061-1068.

Martin, P. J. (1976). Appreciation of music in relation to personality factors. (Order No. U422399). Available from ProQuest Dissertations \& Theses Global. (301326317)

McCrae, R. R. \& Costa, P. T. (1987). Validation of the five-factor model of personality across instruments and observers. Journal of Personality and Social Psychology, 52(1), 81-90. doi:10.1037/00022-3514.52.1.81

McCrae, R. R., \& Costa, P. T., (2008) The five-factor theory of personality. In O. P. John, R. W. Robins \& L. A. Pervin (Eds.), Handbook of personality: Theory and research (3rd ed.) New York, NY: Guilford Press.

McCrae, R. R., \& John, O. P. (1992). An introduction to the five-factor model and its applications. Journal of personality, 60(2), 175-215. doi:10.1111/j.14676494.1992.tb00970.x.

Myers, I. B. (1998). Introduction to type $\left(6^{\text {th }}\right.$ ed.) Mountain View, CA: Consulting Psychologists Press. 
Norman, W. T. (1963). Toward an adequate taxonomy of personality attributes: Replicated factor structure in peer nomination personality ratings. Journal of Abnormal and Social Psychology, 66, 574-583.

Payne, P. D. (2009). An investigation of relationships between timbre preference, personality traits, gender, and music instrument selection of public school band students (Doctoral dissertation). Available from ProQuest Dissertations \& Theses database. (304979970)

Perlovsky, L. (2010). Musical emotions: Functions, origins, evolution. Physics of Life Reviews, 7(1), 2-27. http://doi.org/10.1016/j.plrev.2009.11.001

Psychometric-success.com (2017). Retrieved March 3, 2017. http://www.psychometricsuccess.com/personality-tests/personality-tests-big-5-aspects.htm

Raven, J., Raven, J. C., Court, J.H. (1998). Manual for Raven's Progressive Matrices and Vocabulary Scales. Section 4: The Advanced Progressive Matrices. San Antonio, TX: Harcourt Assessment.

Reardon, C. M. (2009). Differences in Myers-Briggs personality types among high school band, orchestra, and choir members (Order No. 1484428). Available from ProQuest Dissertations \& Theses Global. (219956946). Retrieved from https://search.proquest.com/docview/219956946? accountid=14745

Rentfrow, P. J. \& Gosling, S. D. (2003) The do re mi's of everyday life: The structure and personality correlates of music preferences. Journal of Personality and Social Psychology, 84, 1236-1256.

Roberts, B., Wood, D., \& Caspi, A. (2008). The development of personality traits in adulthood. In O. P. John, R. W. Robins \& L. A. Pervin (Eds.), Handbook of personality: Theory and research (3rd ed.) NY: Guilford Press.

Russell, R. J. \& Wells, P. A. (1991). Personality similarity and quality of marriage. Personality and Individual Differences. 12(5), 407-412. https://doi.org/10.1016/01918869(91)90057-I.

Russel, R. J. \& Wells, P.A. (1994). Predictors of happiness in married couples. Personality and Individual Differences. 17(3), 313 - 321. https://doi.org/10.1016/0191-8869(94)90279-8.

Srivastava, S. (2017). Measuring the Big Five Personality Factors. Retrieved March 5, 2017 from http://psdlab.uoregon.edu/bigfive.html.

Steele, A. L., \& Young, S. (2011). A descriptive study of Myers-Briggs personality types of professional music educators and music therapists with comparisons to undergraduate majors. Journal of Music Therapy, 48, 55-73. doi10.1093/jmt/48.1.55.

Storr, A. (1972). The dynamics of creation. London: Secker and Warburg. 
Viswesvaran, C. \& Ones, D. (2000). Measurement error in "Big Five Factors" personality assessment: Reliability generalization across studies and measures. Educational and Psychological Measurement, 60(2), 224-235. doi:10.1177/00131640021970475

Welborn, D. C. (2012). Adult community bands and personality type as defined by the MyersBriggs: A study of the personality types and music participation preferences of adult musicians (Order No. 3534840). Available from ProQuest Dissertations \& Theses Global. (1277600944).

Wills, G. I. (1984). A personality study of musicians working in the popular field. Personality and Individual Differences, 5, 359-360.

Woodworth, R. S. (1919). Examination of emotional fitness for war. Psychological Bulletin, 15, 59-60.

Wubbenhorst, T. M. (1994). Personality characteristics of music educators and performers. Psychology of Music, 22, 63-74. doi:10.1177/0305735694221006.

Wych, G. M. (2012). Gender and instrument associations, stereotypes, and stratification: A literature review. Update: Applications of Research in Music Education, 30, 22-31. doi: $1177 / 8755123312437049$.

Young, S. (2001). Non-music majors who persist in selected college marching bands: Demographic characteristics, and Myers-Briggs personality types (Doctoral dissertation) Available from ProQuest Dissertations \& Theses database. (304706767)

Zhukov, K. (2007). Student learning styles in advanced instrumental music lessons. Music Education Research, 9(1), 111-127. doi:10.1080/14613800601127585 


\section{APPENDIX A}

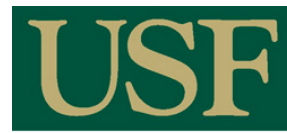

UNIVERSITY OF

SOUTH FLORIDA

\section{INFORMED CONSENT TO PARTICIPATE IN RESEARCH}

Information to Consider Before Taking Part in this Research Study

IRB Study \# Pro00029829

Researchers at the University of South Florida (USF) study many topics. To do this, we need the help of people who agree to take part in a research study. This form tells you about this research study. We are asking you to take part in a research study that is called: Personality Traits and Music Experience in Collegiate and Community Ensembles. The person who is in charge of this research study is Tracy Torrance. This person is called the Principal Investigator.

\section{PURPOSE OF THE STUDY}

You are being asked to participate because you are either a member of a music ensemble or not a member of a music ensemble. The purpose of this study is to determine personality types of individuals who participate in collegiate and community music ensembles.

\section{STUDY PROCEDURES}

If you take part in this study, you will be asked to complete an online personality survey at your convenience. The survey should take between 7-10 minutes to complete. All data will be collected anonymously. The research will be done at the University of South Florida in the Music Building.

\section{ALTERNATIVES/VOLUNTARY PARTICIPATION/WITHDRAWAL}

You have the alternative to choose not to participate in this research study.

You should only take part in this study if you want to volunteer; you are free to participate in this research or withdraw at any time. There will be no penalty or loss of benefits you are entitled to receive if you stop taking part in this study. If you are a student, your decision to participate or not to participate will not affect your student status (course grade).

\section{BENEFITS and RISKS}

Please do not make statements that cannot be proved; note, compensation or extra credit is not considered a benefit in research studies. You will receive no benefit from this study. This research is considered to be minimal risk. 
We will not pay you for the time you volunteer while being in this study.

\section{PRIVACY \& CONFIDENTIALITY}

We must keep your study records as confidential as possible. However, certain people may need to see your study records. By law, anyone who looks at your records must keep them completely confidential. The only people who will be allowed to see these records are: Principal Investigator and research team.

Examples of others who may see the data:

The University of South Florida Institutional Review Board (IRB), government offices such as, The Department of Health and Human Services (DHHS)

\section{CONTACT INFORMATION}

If you have any questions please contact the USF IRB at (813) 974-5638 or the Principal Investigator at ttorranc@mail.usf.edu.

We may publish what we learn from this study. If we do, we will not let anyone know your name. We will not publish anything else that would let people know who you are. You have been given a copy of this form.

I freely give my consent to take part in this study. I understand that by proceeding with this survey that I am agreeing to take part in research and I am 18 years of age or older. 
APPENDIX B

\section{CONFIDENTIAL DEMOGRAPHIC QUESTIONNAIRE (COLLEGIATE)}

Gender (circle one): Male Female Age: ___ Handedness (circle one): Right Left

Ethnicity/Race (Please circle one): Non-Hispanic/White Black/African American

Latino Asian/ Pacific Islander Middle Eastern

American Indian/Alaskan Native Multi-Racial:

Other:

Ethnicity (Please circle one): Hispanic/Latino Non-Hispanic/Non-Latino

Number of students enrolled at your university/college (Please circle one):

5,000 or under $\quad 5,000-10,000 \quad 10,000-20,000 \quad 20,000-30,000 \quad 30,000$ or more

Year (circle one): Freshman Sophomore Junior Senior Master Doctoral

Major: Concentration:

If employed, part-time or full-time, what is your profession?

Primary instrument/voice part?

At what age did lessons commence?

How many years have you played primary instrument/sung?

Primary ensemble of participation:

How many years have you participated in ensembles? 
How many hours do you practice/play per week outside of rehearsal? 


\section{APPENDIX C: \\ CONFIDENTIAL DEMOGRAPHIC QUESTIONNAIRE (COMMUNITY)}

Gender (circle one): Male Female Age: ___ Handedness (circle one): Right Left

Ethnicity/Race (Please circle one): Non-Hispanic/White Black/African American

Latino Asian/ Pacific Islander Middle Eastern American

Indian/Alaskan Native Multi-Racial:

Other:

If employed, part-time or full-time, what is your profession? If retired, what was your previous profession?

Years in education (Please circle one): High school diploma or equivalent Some college Bachelor's degree Master's Degree PhD/MD or equivalent

Primary instrument/voice part?

At what age did you begin formal training?

How many years have you played primary instrument/sung?

Primary ensemble of participation:

How many years have you participated in ensembles?

How many hours do you practice/play per week outside of rehearsal? 


\section{ADDENDIX D: \\ BIG FIVE PERSONALITY INVENTORY}

\section{Instructions:}

In the table below, please rate how much you agree or disagree with each statement using a scale of $\mathbf{1}-5$ as follows: $\mathbf{1}=$ Disagree, $\mathbf{2}=$ Slightly Disagree, $\mathbf{3}=$ Neutral, $\mathbf{4}=$ Slightly Agree, $\mathbf{5}=$ Agree. Place your answer in the "Rating" column.

\begin{tabular}{|c|c|c|c|}
\hline Rating & I see myself as someone who... & Rating & I see myself as someone who ... \\
\hline & 1. Is the life of the party. & & 26. Has little to say. \\
\hline & 2. Feels little concern for others. & & 27. Has a soft heart. \\
\hline & 3. Is always prepared. & & $\begin{array}{l}\text { 28. Often forgets to put things back in } \\
\text { their place. }\end{array}$ \\
\hline & 4. Gets stressed out easily. & & 29. Gets upset easily. \\
\hline & 5. Has a rich vocabulary. & & 30. Does not have a good imagination. \\
\hline & 6. Doesn't talk a lot. & & $\begin{array}{l}\text { 31. Talks to a lot of different people at } \\
\text { parties. }\end{array}$ \\
\hline & 7. Is interested in people. & & 32. Is not really interested in others. \\
\hline & 8. Leaves my belonging around. & & 33. Likes order. \\
\hline & 9. Is relaxed most of the time. & & 34. Changes my mood a lot. \\
\hline & $\begin{array}{l}\text { 10. Has difficulty understanding abstract } \\
\text { ideas. }\end{array}$ & & 35. Is quick to understand things. \\
\hline & 11. Feels comfortable around people. & & $\begin{array}{l}\text { 36. Doesn't like to draw attention to } \\
\text { myself. }\end{array}$ \\
\hline & 12. Insults people. & & 37. Takes time out for others. \\
\hline & 13. Pays attention to details. & & 38. Shirks my duties. \\
\hline & 14. Worries about things. & & 39. Has frequent mood swings. \\
\hline & 15. Has a vivid imagination. & & 40. Uses difficult words. \\
\hline & 16. Keeps to the background. & & $\begin{array}{l}\text { 41. Doesn't mind being the center of } \\
\text { attention. }\end{array}$ \\
\hline & 17. Sympathizes with others' feelings. & & 42. Feels others' emotions. \\
\hline & 18. Makes a mess of things. & & 43. Follows a schedule. \\
\hline & 19. Seldom feels blue. & & 44. Gets irritated easily. \\
\hline & 20. Is not interested in abstract ideas. & & 45. Spends time reflecting on things. \\
\hline & 21. Starts conversations. & & 46. Is quiet around others. \\
\hline
\end{tabular}




\begin{tabular}{|l|l|l|l|}
\hline & $\begin{array}{l}\text { 22. Is not interested in other people's } \\
\text { problems. }\end{array}$ & & 47. Makes people feel at ease. \\
\hline & 23. Gets chores done right away. & & 48. Is exacting in my work. \\
\hline 24. Is easily disturbed. & & 49. Often feels blue. \\
\hline & 25. Has excellent ideas. & 50. Is full of ideas. \\
\hline
\end{tabular}




\section{APPENDIX E}

\section{USF}

UNIVERSITY OF

SOUTH FLORIDA
RESEARCH INTEGRITY AND COMPLIANCE

Institutional Review Boards, FWA No. 00001669

12901 Bruce B. Downs Blvd., MDC035 • Tampa, FL 33612-4799

(813) 974.5638 • FAX (813) 974.7091

April 7, 2017

Tracy Torrance

School of Music

4202 E Fowler Ave

Tampa, FL 33620

\section{RE: Exempt Certification}

IRB\#: Pro00029829

Title: Personality Traits and Music Experience in Collegiate and Community Ensembles

Dear Ms. Torrance:

On 4/7/2017, the Institutional Review Board (IRB) determined that your research meets criteria for exemption from the federal regulations as outlined by 45CFR46.101(b):

(2) Research involving the use of educational tests (cognitive, diagnostic, aptitude, achievement), survey procedures, interview procedures or observation of public behavior, unless:

(i) information obtained is recorded in such a manner that human subjects can be identified, directly or through identifiers linked to the subjects; and (ii) any disclosure of the human subjects' responses outside the research could reasonably place the subjects at risk of criminal or civil liability or be damaging to the subjects' financial standing, employability, or reputation.

As the principal investigator for this study, it is your responsibility to ensure that this research is conducted as outlined in your application and consistent with the ethical principles outlined in the Belmont Report and with USF HRPP policies and procedures.

Please note, as per USF HRPP Policy, once the Exempt determination is made, the application is closed in ARC. Any proposed or anticipated changes to the study design that was previously declared exempt from IRB review must be submitted to the IRB as a new study prior to initiation of the change. However, administrative changes, including changes in research personnel, do not warrant an amendment or new application.

Given the determination of exemption, this application is being closed in ARC. This does not limit your ability to conduct your research project.

We appreciate your dedication to the ethical conduct of human subject research at the University of South Florida and your continued commitment to human research protections. If you have any questions regarding this matter, please call 813-974-5638. 
Sincerely,

Tom (Thimka, Ph. I).

John Schinka, Ph.D., Chairperson USF Institutional Review Board 


\section{APPENDIX F:}

GRAPHS OF PERSONALITY MEAN SCORES BY CURRENT ENSEMBLE PARTICIPATION (COLLEGIATE, COMMUNITY, OTHER, NO MUSIC ENSEMBLE PARTICIPATIONS)

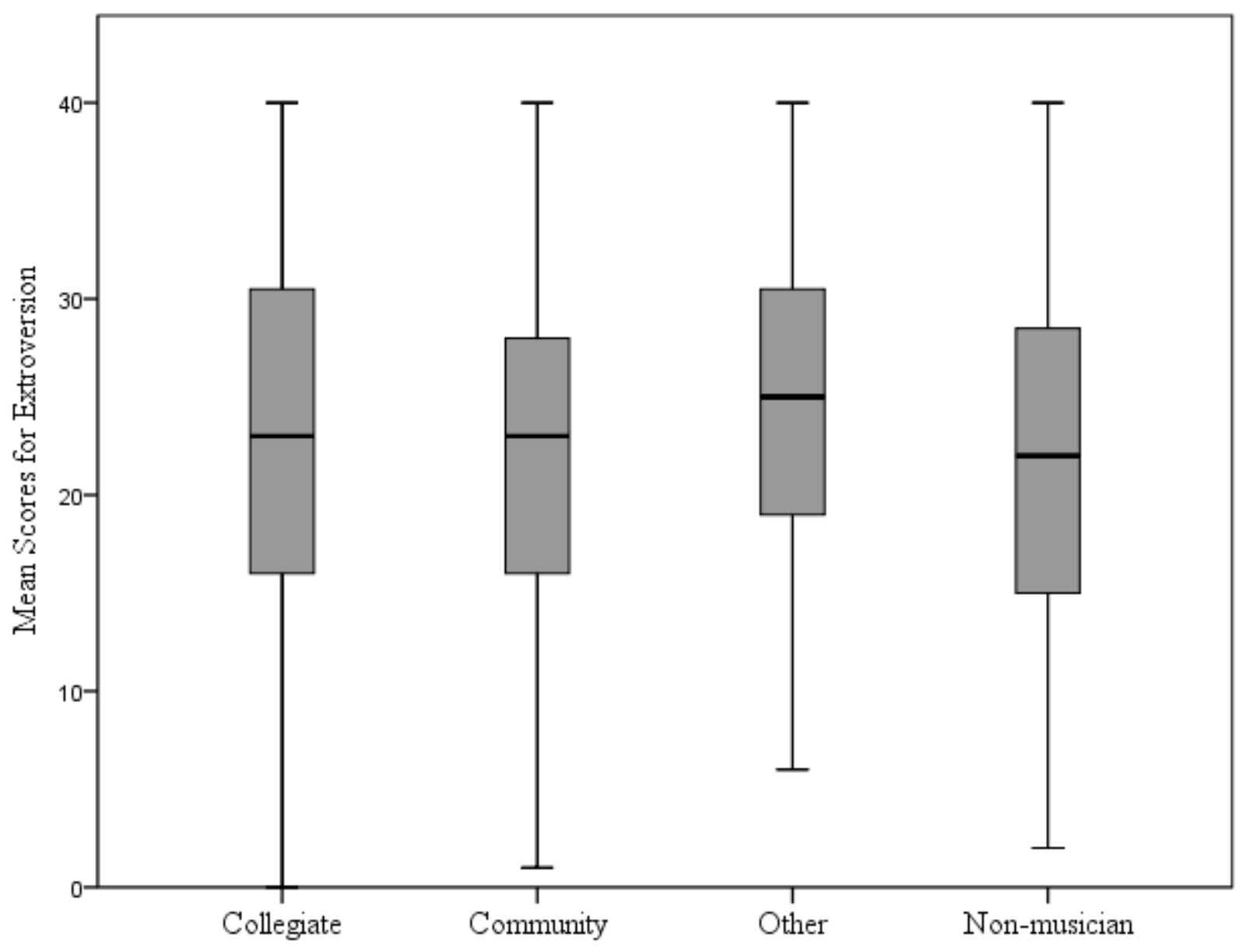

Graph for Extroversion Mean Scores by Current Music Ensemble Participation 


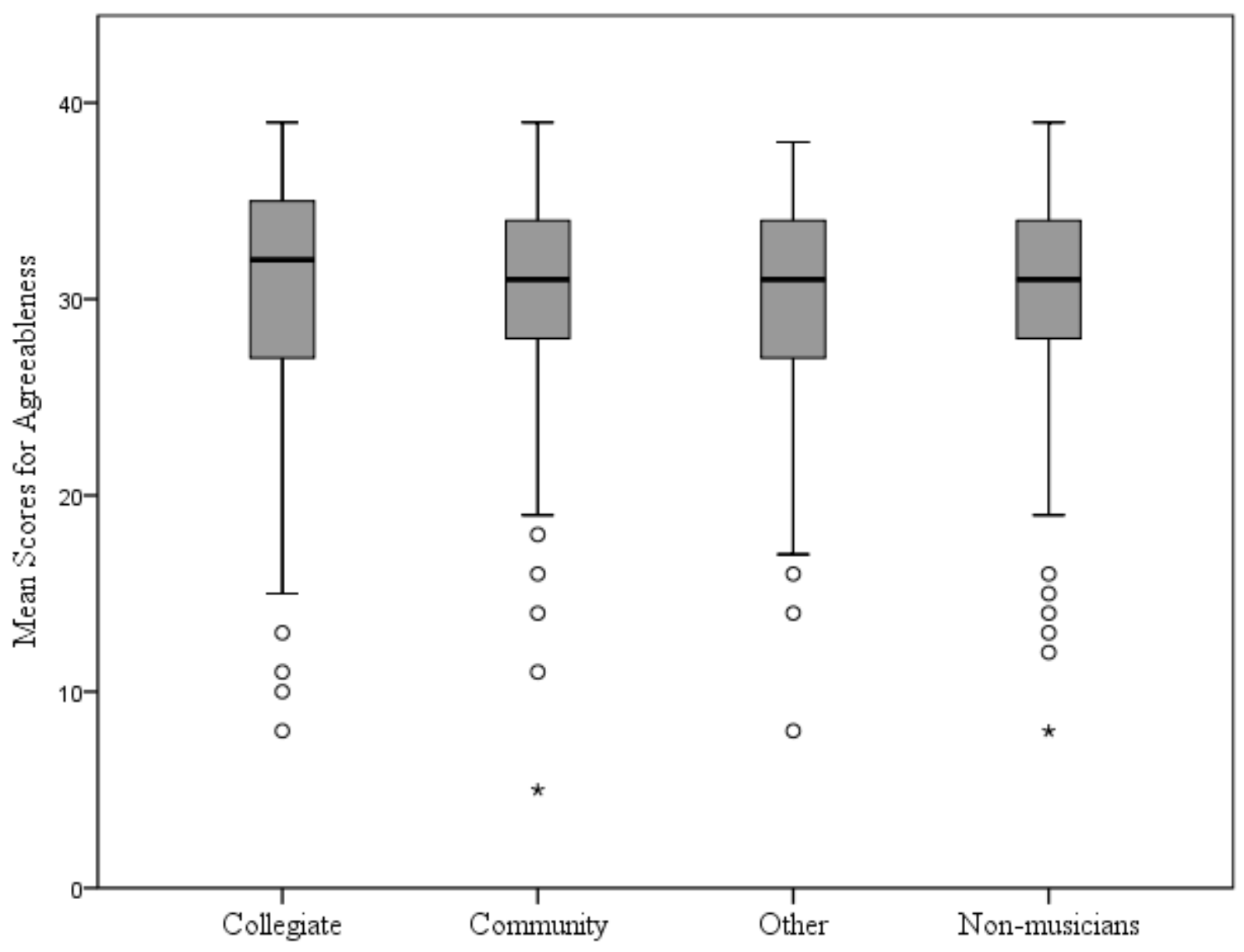

Graph for Agreeableness Mean Scores for Current Music Ensemble Participation 


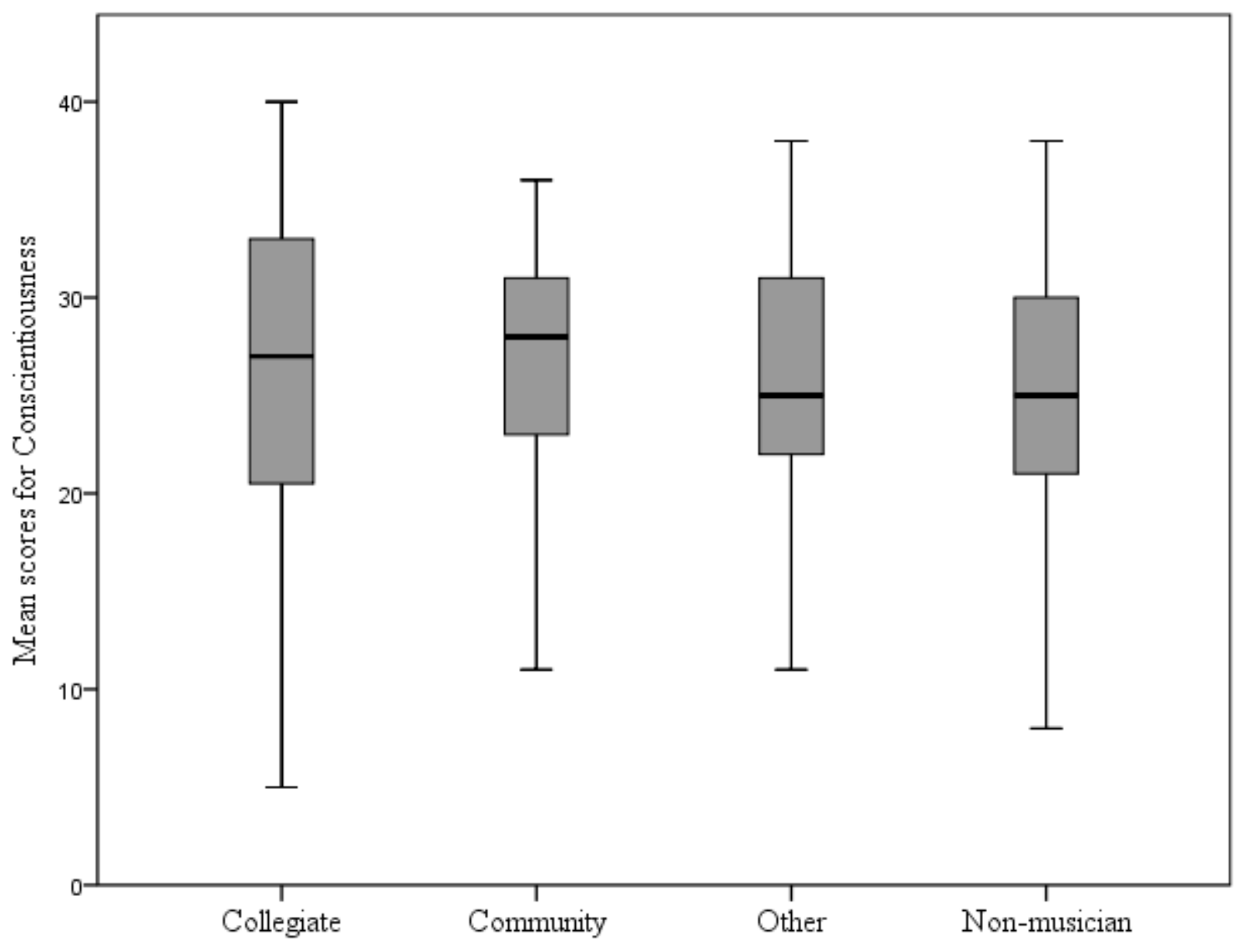

Graph for Conscientiousness Mean Scores for Current Music Ensemble Participation 


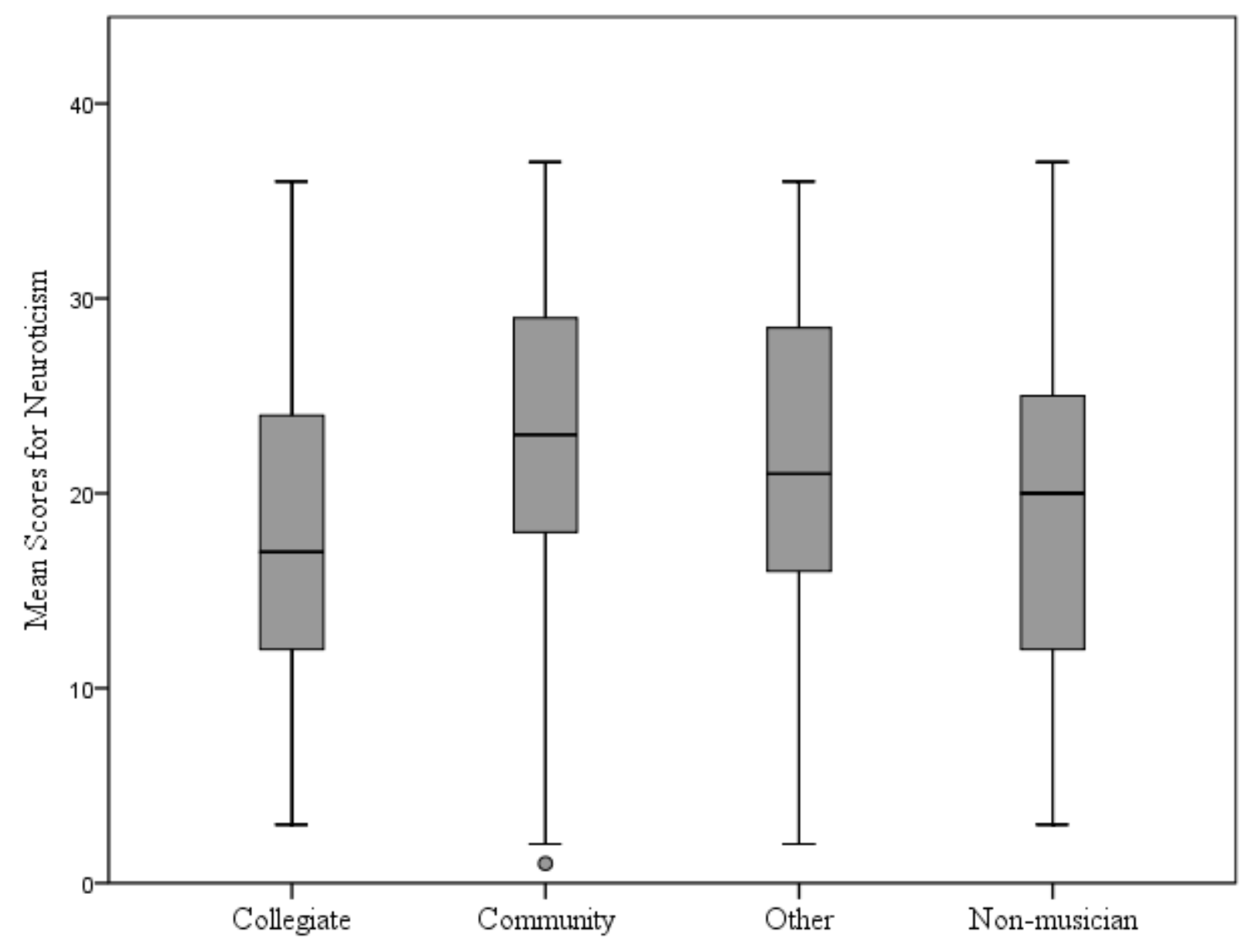

Graph for Neuroticism Mean Scores for Current Music Ensemble Participation 


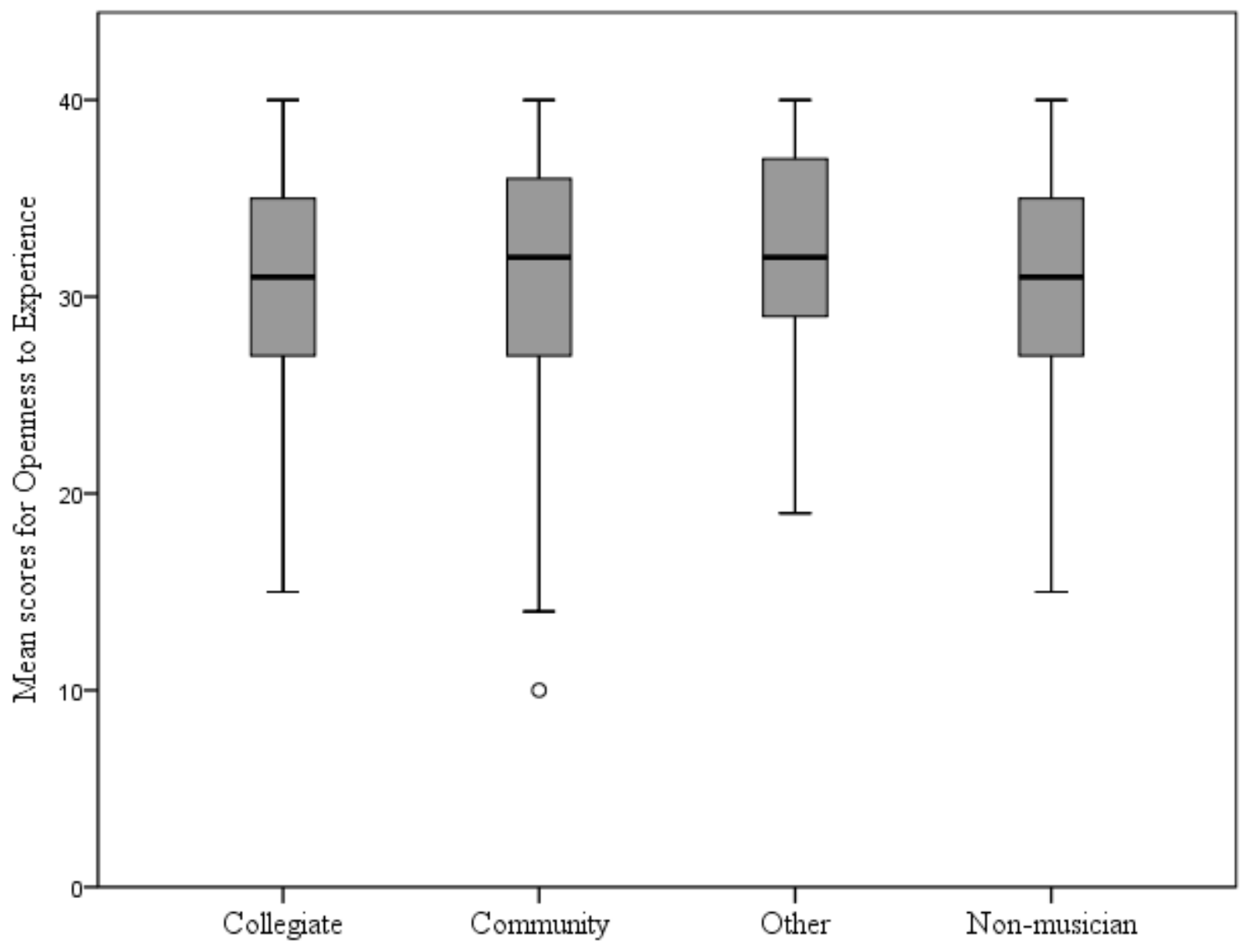

Graph for Openness to Experience Mean Scores for Current Music Ensemble Participation 